\title{
Recessive Mutation Identifies Auxin-Repressed Protein ARP1, Which Regulates Growth and Disease Resistance in Tobacco
}

\author{
Yanying Zhao,, ${ }^{1}$ Cheng Li, ${ }^{1}$ Jun Ge, ${ }^{1}$ Manyu Xu, ${ }^{1}$ Qian Zhu, ${ }^{1}$ Tingquan Wu, ${ }^{1,2}$ An Guo, ${ }^{1,3}$ Junyi Xie, ${ }^{1}$ and \\ Hansong Dong ${ }^{1}$ \\ ${ }^{1}$ State Ministry of Education Key Laboratory of Integrated Management of Crop Pathogens and Insect Pests, Nanjing \\ Agricultural University, Nanjing 210095, China; ${ }^{2}$ Guangdong Academy of Agricultural Sciences, Guangzhou, 510640, China; \\ ${ }^{3}$ Shijiao Agricultural Service Center, Jijiang Qu, Chongqing 401426, China
}

Submitted 27 August 2013. Accepted 25 February 2014.

\begin{abstract}
To study the molecular mechanism that underpins crosstalk between plant growth and disease resistance, we performed a mutant screening on tobacco and created a recessive mutation that caused the phenotype of growth enhancement and resistance impairment (geri1). In the geril mutant, growth enhancement accompanies promoted expression of growth-promoting genes, whereas repressed expression of defense response genes is consistent with impaired resistance to diseases caused by viral, bacterial, and oomycete pathogens. The geril allele identifies a single genetic locus hypothetically containing the tagged GERII gene. The isolated GERII gene was predicted to encode auxin-repressed protein ARP1, which was determined to be $13.5 \mathrm{kDa}$ in size. The $A R P 1 / G E R I 1$ gene was further characterized as a repressor of plant growth and an activator of disease resistance based on genetic complementation, gene silencing, and overexpression analyses. $A R P 1 / G E R I 1$ resembles pathogen-associated molecular patterns and is required for them to repress plant growth and activate plant immunity responses. ARP1/GERI1 represses growth by inhibiting the expression of AUXIN RESPONSE FACTOR gene $A R F 8$, and $A R P 1 / G E R I 1$ recruits the NPR1 gene, which is essential for the salicylic-acid-mediated defense, to coregulate disease resistance. In conclusion, ARP1/GERI1 is an integral regulator for crosstalk between growth and disease resistance in the plant.
\end{abstract}

Disease resistance develops with growth and fitness costs in plants (Dangl et al. 1996; Heidel et al. 2004; Yu et al. 1998; Zhu et al. 2013). Plants utilize multiple strategies to avoid or minimize growth and fitness consequences from defense responses to pathogen attack (Denancé et al. 2013; Mukhtar et al. 2009; Peng et al. 2004; Spoel et al. 2009; Zhu et al. 2013). One of the strategies is the timely inactivation of defense signal transduction to shun the fitness consequences that are asso-

Corresponding author: H. Dong; Telephone: +86 2584399006 , +86 13813928425; Fax: +86 25 84396246; E-mail: hsdong@njau.edu.cn

Y. Zhao and C. Li contributed equally to this work.

* The $e$-Xtra logo stands for "electronic extra" and indicates that nine supplementary figures and four supplementary tables are published and that Figures 1, 9, and 10 appear in color online.

(C) 2014 The American Phytopathological Society ciated with a constitutive defense response in the absence of a pathogen attack (Mukhtar et al. 2009; Spoel et al. 2009). Alternatives may be provided by crosstalk between distinct phytohormone and nonhormone signal transduction pathways assigned to the regulation of plant growth and disease resistance (Han et al. 2013; Li et al. 2012; Wang et al. 2009; Yang et al. 2013; Zhu et al. 2013). A well-known example is auxin- and salicylic acid (SA)-signaling crosstalk, which recruits many previously unappreciated components to balance plant growth and disease resistance (Denancé et al. 2013; Han et al. 2013; Li et al. 2012; Liu and Hu 2013; Wang et al. 2009).

Auxin is a phytohormone that regulates a stunning array of plant growth and development processes (Quint and Gray 2006; Vanneste and Friml 2009), such as embryogenesis (Schiavone and Cooke 1987), root and shoot architecture (Holm and Key 1969; Wilmoth et al. 2005), vegetative growth (Eliasson 1969; Julliard et al. 1992; Wilmoth et al. 2005), floral organogenesis (Julliard et al. 1992), and seed production (Nitsch 1952). These processes may experience dramatic changes in the expression of many auxin-responsive genes under regulation by AUXIN RESPONSE FACTOR (ARF) proteins (Guilfoyle and Hagen 2007; Guilfoyle et al. 1998; Hagen and Guilfoyle 2002). ARF constitute a phylogenic protein family made of 10 to 43 members, as identified thus far, in different plant species (Banks et al. 2011; Ha et al. 2013; Kalluri et al. 2007; Rensing et al. 2008; Zhu et al. 2013). ARF regulate transcription of auxin-responsive genes, which are either induced or repressed by auxin at the transcription level (Lee et al. 2013). Auxin-induced genes fall into several phylogenic categories, such as the auxin/indole-acetic acid-inducible (AUX/IAA), Gretchen Hagen 3 (GH3), and small auxin up RNA $(S A U R)$ gene families (Gray et al. 2001; Guilfoyle et al. 1998; Kumar et al. 2012; Liscum and Reed 2002; Tiwari et al. 2001; Zhu et al. 2013). Auxin-responsive genes classified in an additional category encode auxin-repressed proteins (ARP), and $A R P$ genes constitute a phylogenic gene family distinct from $A U X / I A A, G H 3$, and SAUR (Lee et al. 2013).

Functions of ARP are little understood in relation to the auxin-signaling pathway. Instead, the pathway has been elucidated mainly from the angle of auxin perception and functional interactions between ARF and AUX/IAA proteins (Hayashi 2012; Liscum and Reed 2002; Strader and Nemhauser 2013; Tao et al. 2005). Auxin controls activities of ARF transcription factors by interacting with the F-box protein TIR1 as an auxin receptor (Guilfoyle et al. 1998; Liscum and Reed 2002; Tiwari et al. 2003; Ulmasov et al. 1999). Although the roles of ARF in 
transcriptional regulation of auxin response are repressed by interaction with Aux/IAA transcription repressors, auxin binding enables TIR1 to target Aux/IAAs for proteolysis and release of ARF from the AUX/IAA-ARF complexes, and released ARF turn to regulate the expression of auxin-responsive genes (Gray et al. 2001; Liscum and Reed 2002; Tiwari et al. 2001; Ulmasov et al. 1997). This simple yet powerful pathway makes auxin multifaceted in plant growth and development (Nitsch 1952; Quint and Gray 2006; Vanneste and Friml 2009).

In addition to the role in plant growth and development, auxin also modulates plant resistance to pathogens by crosstalk with microRNA (Navarro et al. 2006). In Arabidopsis, treatment with the peptide flg22 induces microRNA miR393, which acts, in turn, to downregulate the auxin receptor protein TIR1 and repress auxin signaling with a result of preventing a bacterial pathogen from propagation (Navarro et al. 2006). Flg22 is a biologically active peptide derived from flagellin, a critical component of pathogen-associated molecular patterns (PAMPs) in plant-pathogenic bacteria (Asai et al. 2002; Zipfel et al. 2004). Thus, the microRNA repression of auxin signaling contributes to the PAMP-triggered immunity (PTI), an important mechanism of disease resistance in plants (Ausubel 2005; Eckardt 2012; Li et al. 2010; Navarro et al. 2006). PTI is characterized by a number of defense responses, such as the production of reactive oxygen species (ROS) and callose deposition (Daudi et al. 2012; Li et al. 2010; Miya et al. 2007). In several types of ROS (Deng et al. 2010; Piacenza et al. 2007), hydrogen peroxide $\left(\mathrm{H}_{2} \mathrm{O}_{2}\right)$ is more stable (Ashtamker et al. 2007; Paranagama et al. 2010) and is involved in the regulation of PTI and disease resistance (Deng et al. 2011; Miya et al. 2007; Sang et al. 2012; Torres 2010). In addition, PTI is also characterized by the activation of the mitogen-activated protein kinase cascade, shown as induced expression of $M P K$ genes $M P K 3$ through $M P K 6$ and $M P K 11$, especially $M P K 3$ and $M P K 11$, both of which are highly expressed in response to PAMPs (Bethke et al. 2012; Miya et al. 2007; Wan et al. 2008).

In addition to crosstalk with microRNA, auxin also interacts with SA to modulate disease resistance (Denancé et al. 2013; Yang et al. 2013). SA is a phytohormone fully elucidated as a vital signal of systemic acquired resistance (SAR) in plants (Delaney et al. 1994; Ryals et al. 1996). SA signaling for SAR involves an essential role of the NPR1 protein in transcriptional regulation of plant defense responses (An and Mou 2011; Cao et al. 1997; Mukhtar et al. 2009). In plants under pathogen attack, the SA content is elevated to trigger the activity of NPR1 on defense response genes such as pathogenesisrelated (PR) genes (An and Mou 2011). This response accompanies repression of the auxin-signaling pathway by SA signaling in Arabidopsis (Wang et al. 2007). In the plant, SA stabilizes Aux/IAAs, protects them from degradation, and represses auxin signal transduction (Wang et al. 2007). The SA repression of auxin signaling results in enhanced expression of NPR1regulated defense response genes and plant resistance-inhibiting pathogen growth. Therefore, the repression of the auxinsignaling pathway is an integral component of the SA- or NPR1-regulated disease resistance (Denancé et al. 2013; Wang et al. 2007).

Auxin also affects SA signaling and modulates disease resistance (Ghanashyam and Jain 2009; Truman et al. 2010; Wang et al. 2007). The application of auxin or its synthetic form, 1-naphthalacetic acid (NAA), promotes pathogen growth and aggravates disease severities (Truman et al. 2010; Wang et al. 2007), consistent with defense compromise by the TIRl gene overexpression (Navarro et al. 2006). By contrast, auxin insensitivity compensates for the defense impairment in the transgenic Arabidopsis NahG plant, which cannot accumulate SA and, there- fore, is highly susceptible to pathogens (Lawton et al. 1995; Wang et al. 2007). Susceptibility to pathogens is also increased by overexpression of TRANSPARENT TESTA GLABRA (TTG2), a WD40 domain-containing protein that is an activator of plant development and a repressor of disease resistance $(\mathrm{Li}$ et al. 2012). In tobacco, TTG2 regulates growth and development by promoting the expression of the ARF\& gene (Zhu et al. 2013). Inversely, TTG2 suppresses disease resistance by retaining the NPR1 protein in the cytoplasm, sequestering NPR1 from the nucleus, and preventing its regulatory role in $P R$ gene expression ( $\mathrm{Li}$ et al. 2012). Therefore, the repression of NPR1-regulated disease resistance involves antagonistic crosstalk between the resistance and development regulators at the nucleocytoplasmic trafficking process (Li et al. 2012; Lü et al. 2011).
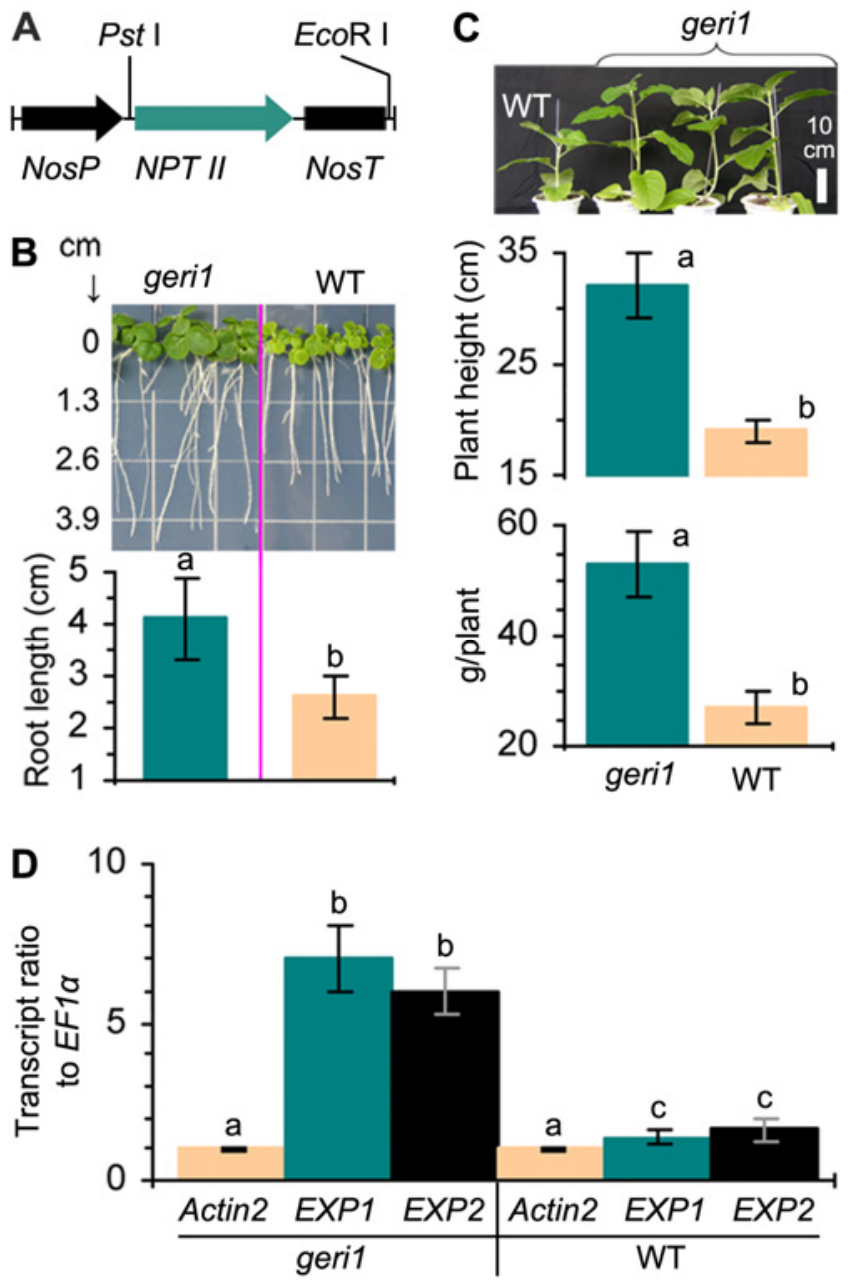

Fig. 1. The tobacco geril mutant is enhanced in growth and EXP gene expression. A, Part of the T-DNA vector used in the insertional mutagenesis. Nos $P$ and NosT refer to the promoter and transcription terminator, respectively, from the gene encoding nopaline synthase; NPT II encodes kanamycin (Kan) resistance used for transgenic plant screening; restriction enzymes shown on top are useful for subsequent T-DNA insert analysis. B, Photos and bar graphs showing extents of root growth for 20 days on medium. WT = wild type. C, Plants were photographed and growth extents were quantified after growth for 60 days (15 days after seed germination in pots containing potting soils and an additional 45 days after transfer to new pots). D, Quantification of EXP1 and EXP2 expression in leaves of plants from C. Gene expression was analyzed by real-time reverse-transcriptase polymerase chain reaction using the constitutively expressed EF1 $\alpha$ and Actin2 genes as references. Data shown in B and D are mean values \pm standard deviation bars $(n=$ 9 experimental repeats; 15 plants per repeat). Different letters on bar graphs indicate significant differences by one-way analysis of variance and least significant difference test $(P<0.01)$. 
Based on information stated above, auxin-SA crosstalk in balancing plant growth and disease resistance has been shown to take place at stages of the signal perception (Navarro et al. 2006; Wang et al. 2007), nucleocytoplasmic trafficking of the signaling regulator partners (Li et al. 2012; Lü et al. 2011; Palma et al. 2005), and transcriptional regulation of auxin responses versus SA responses (Han et al. 2013; Li et al. 2012; Wang et al. 2007). Additional components, such as ARF and ARP, also may be involved in auxin crosstalk to SA (Denancé et al. 2013; Han et al. 2013; Li et al. 2012; Liu and Hu 2013; Wang et al. 2009). For instance, the AUX/IAA stabilization by SA (Wang et al. 2007) may prevent ARF release from the ARF-AUX/IAA complex and, thus, inhibit transcriptional activation of auxin-responsive genes (Gray et al. 2001; Liscum and Reed 2002). However, none of the ARF has been implicated in coregulation of plant growth and disease resistance until now.

In this study, we utilized the T-DNA tagging protocol to identify previously unappreciated regulators for plant growth and disease resistance crosstalk. Performance of the protocol on tobacco (Nicotiana tabacum) resulted in the generation of a recessive mutation at the $A R P I$ gene allele, which allowed for isolation of the wild-type (WT) $A R P 1$ gene. We show that $A R P 1$ is a repressor of vegetative growth and an activator of disease resistance in the plant. We present evidence that ARPI plays an essential role in coregulation of plant growth and disease resistance. We also elucidate that $A R P 1$ regulates crosstalk between plant growth repression and PTI development in response to the bacterial PAMP-derived peptide flag22 (Asai et al. 2002; Zipfel et al. 2004) and the fungal PAMP chitin (Wan et al. 2008). We further implicate $A R F 8$ and NPRI in the dual effect of $A R P I$ on plant growth and disease resistance.

\section{RESULTS}

\section{Identification of tobacco growth-enhanced and resistance-impaired mutants.}

To obtain tobacco mutants with alterations in growth and disease resistance, we performed insertional mutagenesis in the plant genome by the aid of a binary vector that contains the T-DNA sequence and related accessories (Fig. 1A). Transformation of the tobacco N. tabacum 'Xanthi' (NN) with the vector and subsequent screening of 150 transgenic plants identified six T-DNA-insertion lines (Supplementary Fig. S1) based on dual modifications in the vegetative growth and disease resistance (Supplementary Fig. S2). The directed screening strategy resulted in identification of mutants with similar phenotype with respect to growth and disease resistance. Compared with the WT plant, T-DNA-insertion lines were enhanced significantly $(P<0.01)$ in the vegetative growth based on measurements of plant height and fresh weight. However, T-DNA-insertion lines

Table 1. Differences in leaf size between growth-enhanced and resistanceimpaired (geril) and wild-type (WT) plants

\begin{tabular}{lcc}
\hline & \multicolumn{2}{c}{ Leaf size $\left(\mathbf{c m}^{2}\right)$} \\
\cline { 2 - 3 } Leaf position (from base) & geri1 & WT \\
\hline 1 & $8.5 \pm 0.7$ & $6.0 \pm 0.6$ \\
2 & $8.3 \pm 1.0$ & $5.5 \pm 1.0$ \\
3 & $16.4 \pm 2.3$ & $12.6 \pm 1.5$ \\
4 & $22.6 \pm 2.0$ & $15.8 \pm 1.5$ \\
5 & $23.8 \pm 2.0$ & $18.1 \pm 2.0$ \\
6 & $25.0 \pm 2.8$ & $19.5 \pm 2.0$ \\
7 & $22.6 \pm 2.2$ & $16.0 \pm 1.5$ \\
8 & $19.3 \pm 2.1$ & $14.5 \pm 1.0$ \\
9 & $18.6 \pm 1.3$ & $7.6 \pm 0.5$ \\
10 & $9.5 \pm 0.8$ & $\cdots$ \\
11 & $3.2 \pm 0.3$ & $\ldots$ \\
\hline
\end{tabular}

resembled the WT plant in the reproductive development. For example, all plants flowered almost simultaneously (at approximately 75 days after seed germination) and produced fruit with similar quantities of seed production (approximately 1,800 seeds per pepo) under conditions in this study. In the inoculation experiments, T-DNA-insertion lines were more susceptible than the WT plant to Tobacco mosaic virus (TMV), hollow stalk pathogen Pectobacterium carotovorum subsp. carotovora, and black shank pathogen Phytophthora parasitica var. nicotianae. TMV, Pectobacterium carotovorum subsp. carotovora, and Phytophthora parasitica var. nicotianae belong to viral, bacterial, and oomycete plant pathogens, respectively. They caused necrosis symptoms on leaves of all plants. However, the symptom severities were significantly $(P<0.01)$ aggravated in T-DNAinsertion lines compared with the WT plant, indicating that T-DNA-insertion lines were impaired in resistance to the different pathogens. Therefore, those T-DNA-insertion lines were designated as growth-enhanced and resistance-impaired (geri) mutants. The mutant line geril was used in further studies because it acquired the most outstanding levels of growth enhancement and resistance impairment.

\section{The geril mutant displays enhanced growth and impaired SAR.}

The geril mutant was compared with the WT plant in terms of the vegetative growth and the expression of growth-promoting genes EXP1 and EXP2, which encode the expansin proteins required for plant growth (Chen et al. 2008; Wu et al. 2007). Vertical cultivation of geril and WT seedlings on Murashige and Skoog (MS) agar medium indicated a marked difference between both plants in root growth and branching after 20 days (Fig. 1B). Average number of root branches was six and three in geril and WT plants, respectively. Average root length of geril was approximately 1.6 times of that of the WT plant (Fig. 1B). A similar difference was found in growth vigor of plants in pots. As observed at 60 days after seed germination, the geril mutant grew much better than the WT plant with respect to plant height and fresh weight (Fig. 1C). The mutant had two more half-expanded leaves and the size of leaves at equivalent positions was also larger than the WT plant (Table 1). In geril, moreover, EXP1 and EXP2 were highly expressed in contrast to the steady-state levels of expression in the WT plant (Fig. 1D). These analyses suggest that growth enhancement is a consistent phenotype of the geril mutant.

Based on the inoculation experiments performed on 45-dayold plants, the resistance to TMV, Pectobacterium carotovorum subsp. carotovora, and Phytophthora parasitica var. nicotianae was suppressed in the geril mutant compared with the WT plant. At every time point during $72 \mathrm{~h}$ after inoculation, the TMV coat protein $(C P)$ gene encoding the $\mathrm{CP}$ was expressed at a higher level, indicating better multiplication of the virus, in leaves of geril in contrast to WT (Fig. 2A). As a result, TMV caused much heavier disease symptoms, shown as larger quantities of necrotic lesions (Fig. 2B) and greater values of the lesion to leaf area ratio (Fig. 2C), on leaves of geril than that on the WT (Fig. 2B). Pectobacterium carotovorum subsp. carotovora caused heavier infection in geril than in WT (Fig. 2D to F). During $72 \mathrm{~h}$, the multiplication rate of P. carotovorum subsp. carotovora in geril leaves remained higher than in the WT (Fig. 2D). Although WT leaves exhibited brighter water-soaked spots, mutant geril leaves incurred severe necrotic lesions (Fig. 2E). The average size of necrotic lesions on geril leaves was tenfold the lesion size on WT (Fig. 2F). Phytophthora parasitica var. nicotianae was also highly virulent to geril (Fig. 2G to I). Within 72 h, P. parasitica var. nicotianae propagated larger quantities of spores on leaves of geril, representing a better capability of multiplication inside 
the plant leaves (Fig. 2G). P. parasitica var. nicotianae caused large necrotic lesions around the inoculation sites on surfaces of geril leaves, whereas the oomycete only caused chlorosis surrounding relatively small necrotic lesions on WT leaves (Fig. 2G to I). In geril, moreover, aggravated diseases were correlated with reduced expression of the $P R-1 a$ and $P R-2 a$ genes, which are molecular markers of SAR (Ryals et al. 1996). Expression levels of both $P R$ genes were lower in leaves of geril versus WT at $48 \mathrm{~h}$ after inoculation with the different pathogens (Supplementary Fig. S3). Therefore, geril is, indeed, an SAR-compromised mutant.

\section{The GERI1 gene encodes auxin-repressed protein ARP1.}

To elucidate the genetic characteristics of the geril allele, we investigated phenotypes of F1 and F2 progenies from the geril $\times$ WT backcross at a large scale (Table 2). In the F1 progeny of this cross, the WT phenotype was observed in the vegetative growth and resistance to TMV, Pectobacterium carotovorum subsp. carotovora, and Phytophthora parasitica var. nicotianae. Subsequently, three F2 progeny groups derived from those F1 plants were examined for segregation of the geril mutant phenotype in the growth and resistance to every pathogen. In each progeny group, a 3:1 ratio of WT to geril mutant phenotype was observed. Together, these data indicate that the geril allele is recessive and identifies a single genetic locus, which hypothetically contains T-DNA-indexed GERII gene.

Because the T-DNA sequence was inserted into the geril genome (Fig. 3A) with a single copy (Fig. 3B), we carried out thermal asymmetric interlaced (TAIL) polymerase chain reaction (PCR) to identify the T-DNA-indexed GERII gene in the geril mutant tobacco genome. This TAIL PCR resulted in the isolation of a 291-bp sequence flanked to the right border of T-DNA from the vector (Fig. 3C). In this flanking sequence, a 269-bp region was found to be an incomplete open reading frame (ORF) highly identical $(99.63 \%)$ with a partial sequence fragment of the Solanaceae virginianum ARPl gene (AY572222.1) (Fig. 3D; Supplementary Fig. S4). To obtain a full-length $A R P 1$ homolog from the WT tobacco plant, we performed rapid amplification of cDNA ends (RACE) on the $3^{\prime}$ terminal end of the sequence from TAIL PCR by using the WT
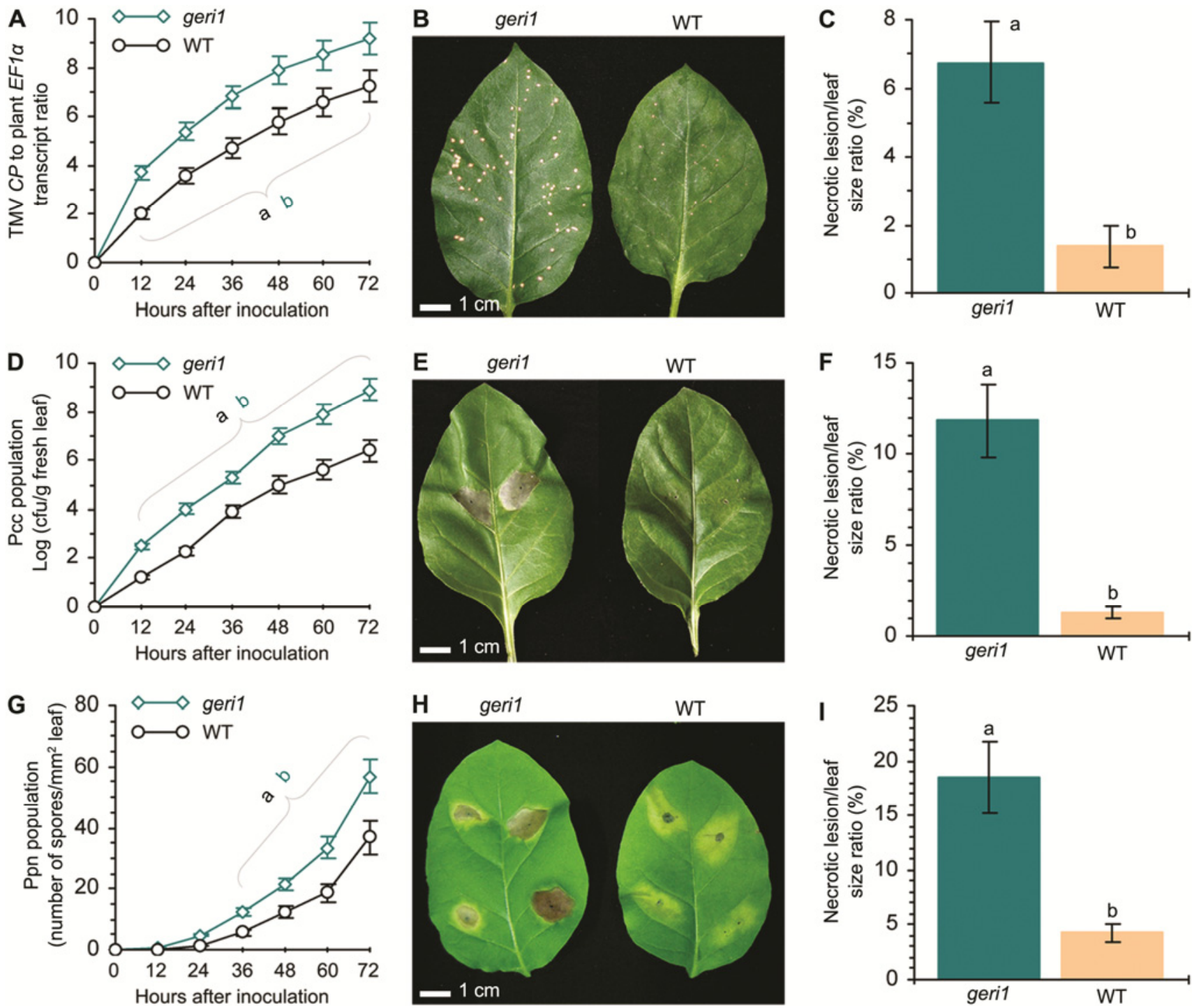

Fig. 2. The geril mutant is compromised in resistance to pathogens. A to $\mathbf{C}$, Assessments of plant infection by Tobacco mosaic virus $(\mathrm{TMV})$; WT $=$ wild type. D to F, Assessments of plant infection by Pectobacterium carotovorum subsp. carotovora (Pcc). G to I, Assessments of plant infection by Phytophthora parasitica var. nicotianae (Ppn). In all assessments, resistance compromises in the mutant were shown as increased severities of infection. In left and right vertical panels, data shown are mean values \pm standard deviation bars ( 9 experimental repeats, 10 plants per repeat). Different letters in curve and bar graphs indicate significant differences by one-way analysis of variance and least significant difference test $(P<0.01)$, and parentheses in curve graphs indicate the range of time points at which differences are significant. 
genomic DNA (Fig. 3E). This RACE protocol yielded a 440bp sequence from the genomic DNA (Fig. 3F and G). By assembling the sequences from TAIL PCR and RACE, we finally obtained the 375-bp full-length ORF of the tobacco $N$. tabacum ARP1/GERI1 gene (Fig. 3G), which is called ARPl hereafter for the sake of simplicity. In addition, we confirmed that the $A R P 1$ gene was repressed by auxin at the transcription level in the WT tobacco and the gene expression was nullified in the geri1 mutant plant (Supplementary Fig. S5A).

The tobacco ARP1 protein contains 125 amino acids and is $13.5 \mathrm{kDa}$ in size. ARP1 homologues are present only in the plant kingdom, not in other organisms. Searches against $\mathrm{Na}$ tional Center for Biotechnology Information (NCBI) protein databases revealed 33 homologues that are more than $80 \%$ identical with the tobacco ARP1 protein in amino acid sequences. The phylogenetic tree indicates relationships of the tobacco ARP1 protein with 20 homologues identified in 10 plant species (Fig. 4A). ARP orthologs from monocotyledons (Fig. 4A, codes 1 to 7) and dicotyledons (Fig. 4A, others) fall into two distinct clades. The tobacco ARP1 protein is highly related to its homologues from $S$. virginianum and Lycopersicon esculentum.

The ARP1 sequence contains several functional motifs (Fig. 4B). They are two casein kinase II phosphorylation sites (3235TGGE and 105-108TVYD), a single glycosaminoglycan attachment motif (36-39SGEG), two protein kinase C phosphorylation sites (40-42SSK and 87-89TKR), and three N-myristoylation sites (33-38GGESGE, 82-87GSNIAT, and 113118 GNTRSK). These motifs are implicated in protein-protein interactions or cellular signal transduction pathways (Dangl and Jones 2001). In addition, 53 to 69 residues in the ARP1 sequence make a proline/threonine-rich motif, which is often involved in plant resistance to pathogens (Dangl and Jones 2001; Datta and Muthukrishnan 1999). All motifs are conserved in

Table 2. Genetic characterization of growth and resistance in growth-enhanced and resistance-impaired $($ geril $) \times$ wild-type $($ WT) cross

\begin{tabular}{|c|c|c|c|c|c|c|}
\hline \multirow[b]{3}{*}{ Generation } & \multicolumn{4}{|c|}{ Number of WT/geril plants in phenotype } & & \\
\hline & & \multicolumn{3}{|c|}{ Resistance to $^{a}$} & \multicolumn{2}{|c|}{ Theoretical $\chi^{2}$} \\
\hline & Growth & TMV & Pectobacterium & Phytophthora & Growth & Resistance \\
\hline F1 & $205 / 0$ & $107 / 0$ & $103 / 0$ & $105 / 0$ & $1: 0$ & $1: 0$ \\
\hline $\mathrm{F} 2$ & $215 / 72$ & $195 / 67$ & $195 / 64$ & $198 / 67$ & $3: 1$ & $3: 1$ \\
\hline
\end{tabular}

${ }^{\mathrm{a}} \mathrm{TMV}=$ Tobacco mosaic virus, Pectobacterium $=$ Pectobacterium carotovorum subsp. carotovora , and Phytophthora $=$ Phytophthora parasitica var nicotianae.
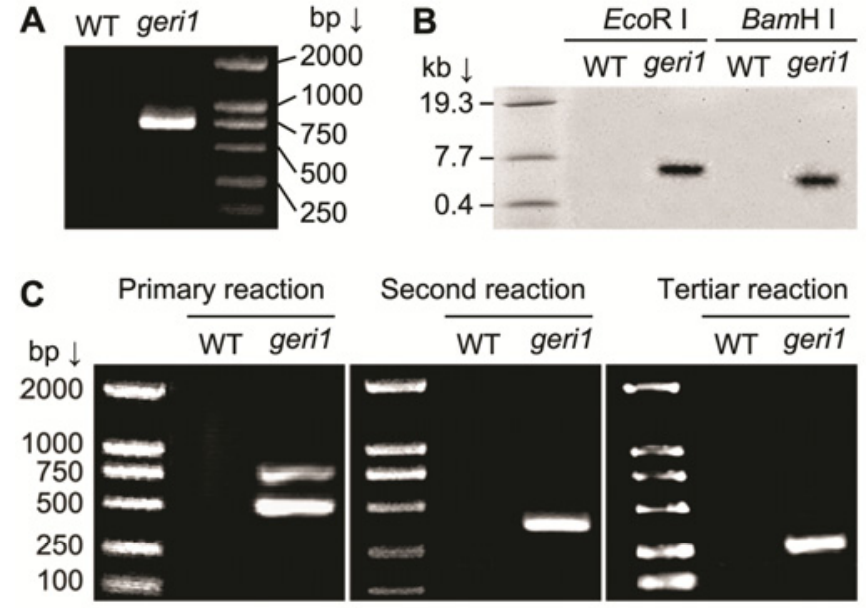

Tertiar reaction

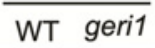

D 5'-ccgccttcagtttaaactatcAGTGTTTGACAGGATATATT GGCGGGTAAAC(1-)ATAGTAGTAGCTAAGAGAGAAG

1-ATGgTGTTGATTGATAAACTTTGgGATGATGTTATGGCTG GTCCCAGCCCTGATAAAGGACTCGGCAAACTAAGAAAAAG СCTCACTGTTCAAACTGCTGGGGAATCATCAGGAGAAGGA TCAAGCAAGTACCAGAGGTCTCTGTCGATGCCGGCAAGTC CGGCGACGCCAGGTACGCCGGTGACGCCGGCAAATATAT CGCCGACGGTGAGGAAAGAGAATGTATGGAGGAGTGTTTT TCACCCAGGAAGCAATCTAGCCACCAAGAG-3' $\leftarrow 291$

$$
(A R P 1) 269>\text { (flanking }
$$
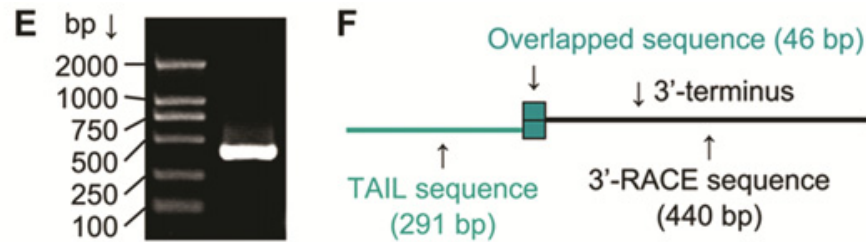

G ATAGTAGTAGCTAAGAGAGAAG

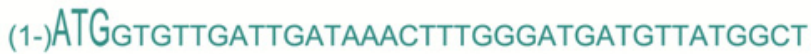
GGTCCCAGCCCTGATAAAGGACTCGGCAAACTAAGAAAAAG CCTCACTGTTCAAACTGCTGGGGAATCATCAGGAGAAGGA TCAAGCAAGTACCAGAGGTCTCTGTCGATGCCGGCAAGTC CGGCGACGCCAGGTACGCCGGTGACGCCGGCAAATATAT

1 (RACE start)

CGCCGACGGTGAGGAAAGAGAATGTATGGAGGAGTGTTTT TCACCCAGGAAGCAATCTAGCCACCAAGAGAATTGGTGCG GAAGTTTTTGACAAGCCСTCTCACCCTAACGCTCССАCTGT TTATGACTGGCTCTACAGTGGGAACACCAGATCTAAGCATC ACGAGAAGTTGTAA(375)GAGTTTTTGGTTGGCAAAAGCAG TTGAAACCTTGGTGTAAATAGTGTTCTTTTCTCTGCGCATG GATTACTGGACTTCCGATCTTTGTTTGCAATTATATGTTTTT TTCTGTTGAGTATTACTTACTTACTACTATGTTGTAAATTAG GTTTTCCTAGCAAGCTTATGAGCTTTAATGGTTATTAATGG ATTTCCAGTTCCAAAGGAAGGTGCTACTATTACTCTACTGT TGTTCGGGGTTTGCTTAGTAAATAAAAAAAAAAAAAAAAAT CGATGTCGACTCGAGTC-440 (RACE terminus)

Fig. 3. The geril allele identifies a T-DNA-indexed ARP1 gene locus. A, Polymerase chain reaction (PCR) analysis of genomic DNA using primers specific to T-DNA; WT = wild type. B, Blot of digested genomic DNA hybridized to the T-DNA-specific probe. $\mathbf{C}$, Thermal asymmetric interlaced (TAIL) PCR analysis of geril genomic DNA. D, Product sequence from the last TAIL PCR reaction. That reaction yielded a 291-nucleotide sequence (indicated by numbers in red) from the geril genome. The front sequence was from the T-DNA insert, including the most $5^{\prime}$-terminal region matched to the primer used in the TAIL PCR reaction. The region shown in watery green was predicted to be partial sequence of the ARP1 gene. E, Product from 3' rapid amplification of cDNA ends (RACE) PCR amplification of cDNA synthesized from the WT RNA sample. F and G, Analyses of TAIL and RACE results. Diagram in F is an overall view on the assembly of TAIL and 3'-RACE sequences. Full length of the assembled sequence is presented in G. The 1 to 375 complete open reading frame of the predicted ARP1 gene is shown in watery green, and the overlap of TAIL and RACE sequences is shaded. 
the eight ARP homologues that are highly identical to each other (Fig. 4B).

All ARP1 homologues are similar in secondary structure. This includes two $\alpha$-helices (occupying $7.32 \%$ proportion of the secondary structure), three $\beta$-sheets $(8.13 \%)$, and six connecting loops $(84.55 \%)$ (Fig. 4B, underlined, underdotted, and regular letters, respectively). The region of 1 to 120 residues shows nonregular secondary structure. Based on these features, we suppose that ARP have multiple functions conserved in the plant kingdom. Until now, however, there has been no study to demonstrate functions of any ARP in plants.
$A R P 1$ is a repressor of plant growth and an activator of disease resistance.

To elucidate the role of the ARPl gene in the vegetative growth of tobacco, we analyzed whether the growth could be altered by gene silencing and overexpression under the background of the WT plant. A virus-mediated posttranscriptional gene silencing (PTGS) system (Fig. 5A) that we performed previously on tobacco ( $\mathrm{Li}$ et al. 2012; Sun et al. 2010; Wang et al. 2009) was utilized to silence the ARPI gene in the concurrent generation of the WT plant. In independent experiments, $A R P 1$ overexpression in the WT plants was achieved under
A

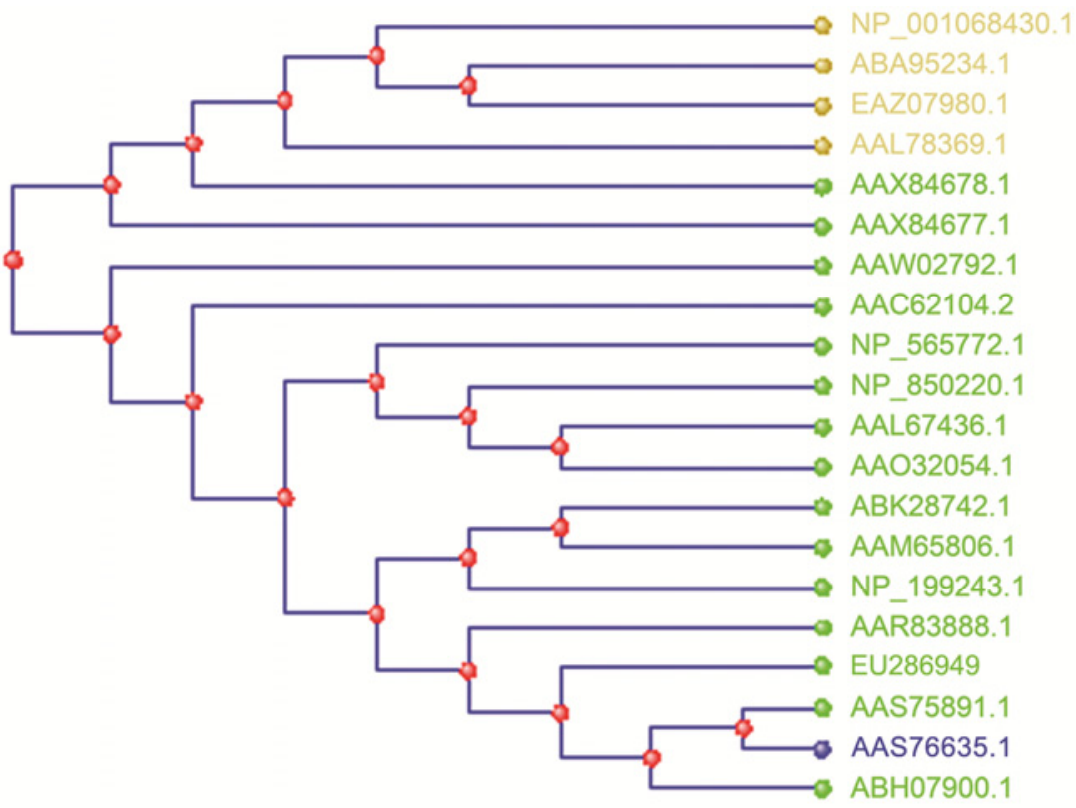

Oryza sativa

Manihot esculenta

Codonopsis lanceolata

Elaeagnus umbellata

Arabidopsis thaliana

Brassica oleracea

B. rapa

A. thaliana

5

Capsicum annuum

Nicotiana tabacum (var. NC89)

18 Solanum virainianum

19 N. tabacum (var. Xanthi,

19 source of NtARP1)

20 Lycopersicon esculentum

B 13 MGVLENLWDDVVAGPRPEAGGRGHLRRISTSLTSLNNTTEGMS-VAGSVSLPASPATP_--VT 59 14 MGVLENLWDDVVAGPRPEAGGRGHLRRISTSLTSLNNTTEGMS-VAGSVSLPASPATP_--VT 59 15 MGVLENLWDDVVAGPRPEAGGRGHLRRISTSLTSLNNTTEGMS-VAGSVSLPASPATP_--VT 59 16 MSATPPTPGTPVT 13 17 MVLIDKLWDDVMAGPQPDNG-LGKLRKSLTVQTGGES-GEGSSKYQRSLSMPASPPTPGTPAT 61 18 MVLIDKLWDDVMAGPSPDKG-LGKLRKSLTVQTAGESSGEGSSKYQRSLSMPASPATPGTPVT 62 19 MVLIDKLWDDVMAGPSPDKG_LGKLRKSLTVQTAGESSGEGSSKYQRSLSMPASPATPGTPVT 62 20 MVLIDKLWDDVMAGPSPDKG-LGKLRKSLTIQTGGES-GEGSSKYQRSLSMPASPPTPGTPVT 61

13 Pg---_sgrkvdvwRsvfhpasnvTtreiganvfDkpshpnsptVydwmysnetRskhrg 115

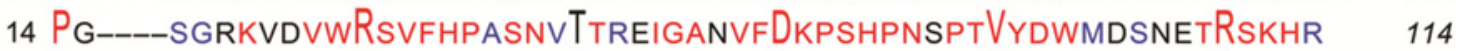

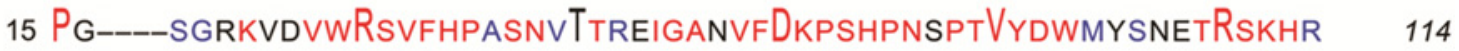
16 PTNTSPTVRKENVWRSVFHPGSNLATRRIGAEVFDKPSHPNAPTVYDWLYSGNTRSKHHEKS 75 17 PTTPSPTASKENVWRSVFHPGSNIATKRIGAQVFDKPSHPNAPTVYDWLYNGNTRSKHHEKC 123 18 PTNISPTVRKENVWRSVFHPGSNLATKRIGAEVFDKPSHPNAPTVYDWLYSGNTRSKHHEKL 124 19 PANISPTVRKENỴRSVFHPGSNLATKRIGAEVFDKPSHPNAPTVYDWLYSGNTRSKHHEKL 124 20 PTNISPTVRKENVWRSVFHPGSNLATRRIGAEVFDKPSHPNAPTVYDWLYSGNTRSKHHEKC 123

Fig. 4. Bioinformatics comparison of ARP1 and its orthologs of different plants. A, A phylogenetic tree. ARP orthologs are indicated by their GenBank accession numbers, codes ( 1 to 20) given in this figure, and sources of plant species. ARP1 has accession number AAS76635.1 in the database and code 19 in this figure. B, Sequence alignments of ARPs in the close clade. Codes are the same as in A. Amino acid resides located at decade sites are shown in taller letters. Amino acid residues identical in all compared orthologs are shown in red, and residues identical in parts of orthologs are shown in blue. Predicted functional motifs are shown in the ARP1 sequence and indicated by residue spans marked with different symbols. Triangles point to casein kinase II phosphorylation sites, downward arrowheads indicate a glycosaminoglycan attachment site, hearts point to protein kinase $\mathrm{C}$ phosphorylation sites, and upward arrowheads indicate $\mathrm{N}$-myristoylation sites. Residues predicted to form $\alpha$-helices and $\beta$-sheets are underlined and underdotted, respectively. 
control by the Cauliflower mosaic virus $35 \mathrm{~S}$ promoter $(P 35 S)$ present in a binary vector (Fig. 5B).

When the gene-silencing unit pBinPlus:Y35 DNA1:2mß: $A R P 1$ (Fig. 5A) was transferred together with the helper vector (Fig. 5A) into the top first heart leaves of 10-day-old plants, the ARPI gene silencing (ARPli) effect became evident 7 days after transformation (Fig. 5C) and was constant throughout the plant development process (Supplementary Fig. S6). ARPli highly enhanced the expression of EXP1 and EXP2 genes because amounts of their transcripts were significantly $(P<0.01)$ greater in germinal apices and heart leaves of $A R P l i$ plants compared with the WT (Fig. 5C). Consistently, ARPli plants significantly $(P<0.01)$ exceeded the WT in the growth vigor of germinal tops and leaves (Fig. 5D). The ARPli plant was almost twice the WT weight at 15 days after transformation and 25 days after seed germination (Fig. 5E). Clearly, the ARPI gene silencing caused an enhancement of plant growth. By contrast, the gene overexpression resulted in a marked suppression to tobacco growth. Compared with the WT, the P35S:ARP1 plant had a greatly elevated amount of the ARPI transcript (Fig. 5C) but was highly impaired in the expression of EXP1 and EXP2 (Fig. 5C). The P35S:ARP1 plant was also impaired in the vegetative growth as observed at 25 days after seed germination (Fig. 5D and E). Therefore, $A R P l$ indeed functions as a repressor of the plant growth.
To elucidate the role of $A R P 1$ in disease resistance, we compared ARPli, P35S:ARP1, and WT plants in terms of responses to inoculation with TMV, Pectobacterium carotovorum subsp. carotovora, and Phytophthora parasitica var. nicotianae. All pathogens propagated to greater populations and caused more severe disease symptoms in ARPli than in the WT plant. The transcript level of TMV $C P$ gene-expressed in leaves of $A R P l i$ was 10 to $20 \%$ more than in leaves of the WT $72 \mathrm{~h}$ after inoculation (Fig. 6A, curve graph). ARPli plants incurred severe symptoms, shown as greater number and size of TMV-caused necrotic lesions on leaves (Fig. 6A, photo and bar graph). In the independent inoculation experiments, Pectobacterium carotovorum subsp. carotovora was found to have greater in planta populations (Fig. 6B, curve graph) and cause more severe symptoms on leaves of $A R P l i$ plants compared with the WT (Fig. 6B, photo and bar graph). And, like TMV and Pectobacterium carotovorum subsp. carotovora, Phytophthora parasitica var. nicotianae also accomplished a higher level of in planta multiplication (Fig. 6C, curve graph) and caused highly aggravating symptoms (Fig. 6C, photo and bar graph) on leaves of $A R P l i$ plants. Therefore, the ARPl gene silencing seriously suppresses plant resistance to diseases caused by the viral, bacterial, and oomycete pathogens. By contrast, the disease resistance was enhanced by $A R P 1$ overexpression. The $P 35 S: A R P 1$ plant incurred significantly $(P<0.01)$ alleviated
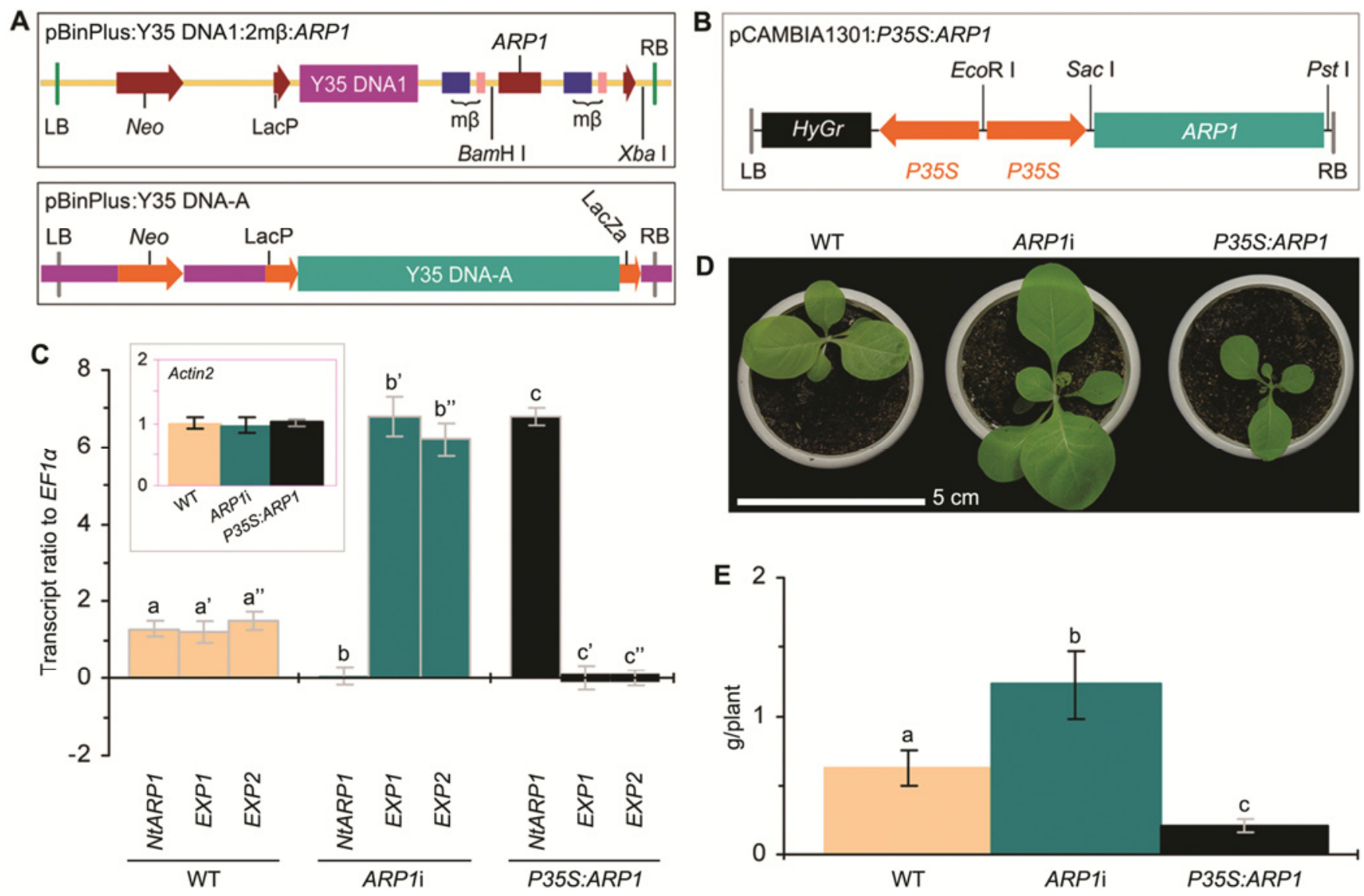

Fig. 5. Opposite effects of $A R P 1$ silencing (RNAi) and overexpression on tobacco growth. A, Diagram of $A R P 1$-silencing unit (top box) and the helper vector (lower box). Elements used in the constructions include neomycin-resistance gene Neo, restriction enzymes, the promoter LacP, and the selective marker LacZa. DNA1 and DNA-A derived from genomic DNA of virus Y35 as well as m $\beta$ truncated from a satellite DNA of Y35 are essential to mediation of RNAi. Both vectors were cotransferred into the most youngest true leaves of 10-day-old plants. B, Part of ARPl-overexpression unit showing elements used in tobacco transformation and subsequent characterization. The selective marker gene $H y G r$ encodes hygromycin resistance. Transformation of the wild-type (WT) tobacco plant resulted in the generation of the ARP1-overexpressing line P35S::ARP1, and its T3 homozygous progenies were in the following experiments. C, Quantification of ARP1 and EXP genes in leaves of ARPli and WT plants tested 7 days after transformation. D, Appearance of 25-day-old plants. E, Fresh weight of plants from D. C and E, Data shown are mean values \pm standard deviation bars $(n=9$ experimental repeats in D and 9 experimental repeats in E, 15 plants per repeat in D and E). Different letters on bar graphs indicate significant differences by two-way (D) or one-way (E) analysis of variance method along with least significant difference test $(P<0.01)$. 
degrees of infection by TMV (Fig. 6A), Pectobacterium carotovorum subsp. carotovora (Fig. 6B), and Phytophthora parasitica var. nicotianae (Fig. 6C) based on pathogen multiplications of these pathogens and resulting disease symptoms on leaves. In addition, transinfection of the geril mutant with the P35S:ARPI fusion gene (Fig. 5B) resulted in substantial expression of $A R P 1$ and markedly decreased infection (Supplementary Fig. S7). These analyses convincingly indicate the essential role of $A R P 1$ in disease resistance.

\section{$A R P 1$ regulates plant responses to flag22 and chitin.}

Flg22 and chitin are well-characterized PAMPs in regard to their dual roles in triggering plant immunity and repressing plant growth (Asai et al. 2002; Göhre et al. 2012; Kaku et al. 2006; Li et al. 2010; Miya et al. 2007; Wan et al. 2008; Zipfel et al. 2004). To obtain information on the relationship between the dual roles that PAMPs and ARPl play in plant growth and immunity, we investigated the vegetative growth and immunity responses of WT, ARPIi, and P35S:ARP1 plants following treatment with flg22 or chitin. The experiments were performed on uniform 25-day-old plants (Fig. 7A), which clearly displayed the growth-promoting effect of $A R P l$ silencing in the $A R P l i$ plant and the growth-inhibitive effect of $A R P I$ overexpression in P35S:ARP1 compared with the WT plant (Fig. 1B). Both PAMPs were used in aqueous solutions to treat 25 day-old plants by spraying over plant tops, and equivalent plants were treated similarly with pure water in the experimental control group. Subsequently, we assessed the vegeta- tive growth, defense responses that are characteristic of PTI, and disease resistance in the differently treated plants.

The effects of flg22 and chitin on the vegetative growth were different in WT, ARPli, and P35S:ARPl based on plant growth appearances (Fig. 7C) and fresh plant weight (Fig. 7D) at day 20 after treatment. Fresh weight of WT plants was decreased significantly $(P<0.01)$ by the treatment with flg 22 or chitin compared with water (Fig 7D). Fresh weight of ARPli plants was similar regardless of treatments (Fig 7D), suggesting that the PAMPs did not function with $A R P 1$ silencing. The vegetative growth of $P 35 S: A R P 1$ was impaired due to ARPI overexpression and further repressed by the treatment with flag22 or chitin compared with the control (Fig 7D), implying the joint role of $A R P 1$ and PAMPs in repressing plant growth. Both flg22 and chitin caused approximately 20 and $40 \%$ decreases in fresh weight of WT and P35S:ARPI plants, respectively (Fig. 7E). Moreover, extents of growth repression were similar in water-treated P35S:ARPI and PAMPs-treated WT plants compared with WT plants treated with water, indicating that $A R P 1$ resembled PAMPs to repress plant growth.

Flag22 and chitin were found to effectively induce PTI responses, including $\mathrm{H}_{2} \mathrm{O}_{2}$ production (Fig. 8A), callose deposition (Fig. 8A), and expression of $M P K$ genes (Fig. 8B) in leaves of WT and P35S:ARPI plants but not the ARPli plant. In particular, among $11 M P K$ genes identified thus far in tobacco (Supplementary Table S1), only $M P K 3$ and $M P K 11$ were regulated by $A R P 1$ because their expression levels were significantly $(P<0.01)$ upregulated by $A R P l$ overexpression and

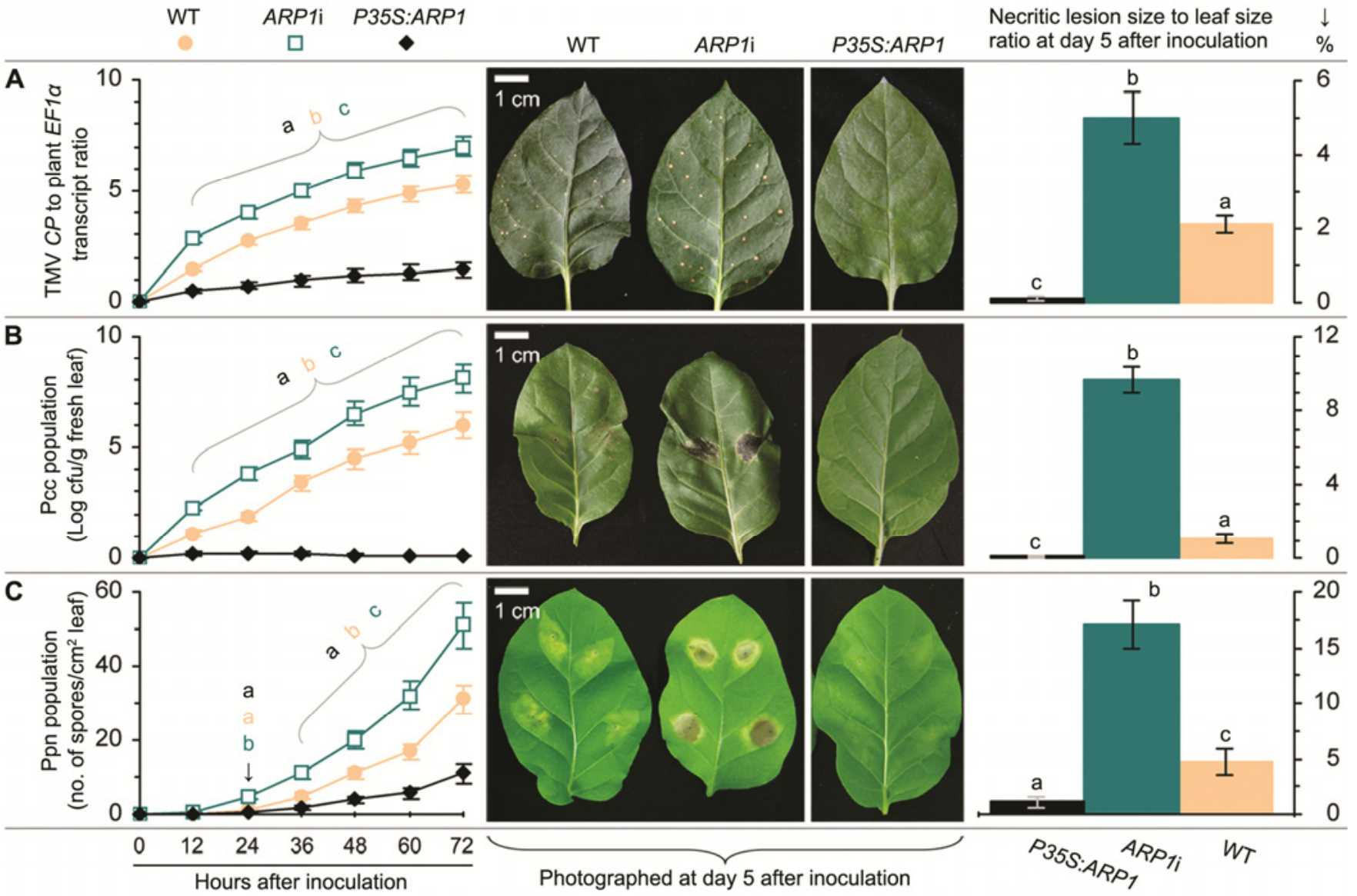

Fig. 6. Opposite effects of ARP1 silencing and overexpression on tobacco resistance to pathogens. A, Assessments of plant infection by Tobacco mosaic virus (TMV); WT = wild type. B, Assessments of plant infection by Pectobacterium carotovorum subsp. carotovora (Pcc). C, Assessments of plant infection by Phytophthora parasitica var. nicotianae (Ppn). In left and right vertical panels, data shown are mean values \pm standard deviation bars $(n=9$ experimental repeats; 10 plants per repeat). Different letters on curve and bar graphs indicate significant differences by one-way analysis of variance and least significant difference test $(P<0.01)$. 
downregulated by $A R P 1$ silencing (Fig. 8B) in contrast to equivalent expression levels of the other nine $M P K$ genes in all plants (Fig. 8B; Supplementary Fig. S8). Apparently, greater amounts of $\mathrm{H}_{2} \mathrm{O}_{2}$ (Fig. 8A), callose (Fig. 8A), and $M P K$ transcripts (Fig. 8B) were found in both WT and P35S:ARP1 plants following treatment with either flag22 or chitin compared with water. Interestingly, visualized $\mathrm{H}_{2} \mathrm{O}_{2}$ and callose abundances (Fig. 8A) and detected quantities of $M P K 3$ and MPK11 transcripts (Fig. 8B) were similar in leaves of P35S: $A R P 1$ plants treated with water and WT plants treated with flg22 or chitin. However, extents by which flag22 and chitin performed to induce $\mathrm{H}_{2} \mathrm{O}_{2}$ and callose production (Fig. $8 \mathrm{~A}$ ) and $M P K$ expression (Fig. 8B) were greater in P35S:ARPI than in the WT plant. By contrast, $\mathrm{H}_{2} \mathrm{O}_{2}$ and callose levels (Fig. 8A) and $M P K$ transcripts (Fig. 8B) were low in ARPli leaves regardless of treatment with water, flg22, or chitin. These observations indicate that ARP1 resembles the PAMPs flg22 and chitin to activate PTI responses and is required for the induction of PTI responses by the PAMPs.

PTI responses were correlated with enhanced resistance to TMV, Pectobacterium carotovorum subsp. carotovora, and Phytophthora parasitica var. nicotianae, or inversely correlated with alleviations of plant infection by those pathogens. In WT and P35S:ARP1 plants, the expression of the TMV $C P$ gene and TMV-caused leaf necrosis, Pectobacterium carotovorum subsp. carotovora population and $P$. carotovorum subsp. carotovora-caused leaf necrosis, and the number of Phytophthora parasitica var. nicotianae spores and $P$. parasitica var. nicotianae-caused leaf necrosis symptoms were significantly $(P<0.01)$ decreased by the plant treatment with flag22 or chitin compared with water (Fig, 8C). Extents by which flag22 and chitin performed to alleviate pathogen infection were greater in P35S:ARPI than in the WT plant. However, the three pathogens performed similarly and caused similar levels of necrosis symptoms in ARPli plants treated with water, flg22, and chitin. These analyses suggest that $A R P 1$ functions through PTI in the opposite effects: i) the enhancement of disease resistance is attributable to the activation of PTI responses in P35S:ARPI and ii) disease resistance is compromised due to arrested PTI responses in the ARPli plant.

\section{$A R P 1$ plays a regulatory role}

on $A R F 8$ and NPRI expression.

ARF8 takes an important part in the auxin-signaling pathway for regulating plant growth (Zhu et al. 2013) while NPR1 essentially regulates the SA-mediated defense (Cao et al. 1997; Mukhtar et al. 2009). We found that the ARF8 and NPR1 genes were oppositely affected by $A R P 1$ silencing and overexpression (Fig. 9A). Compared with the steady-state level of expression in the WT plant, $A R F 8$ expression was enhanced by $A R P l$ i but repressed by $A R P 1$ overexpression ( $P 35 S: A R P 1)$. In contrast, the $N P R I$ expression level was reduced by $A R P l i$ and
A
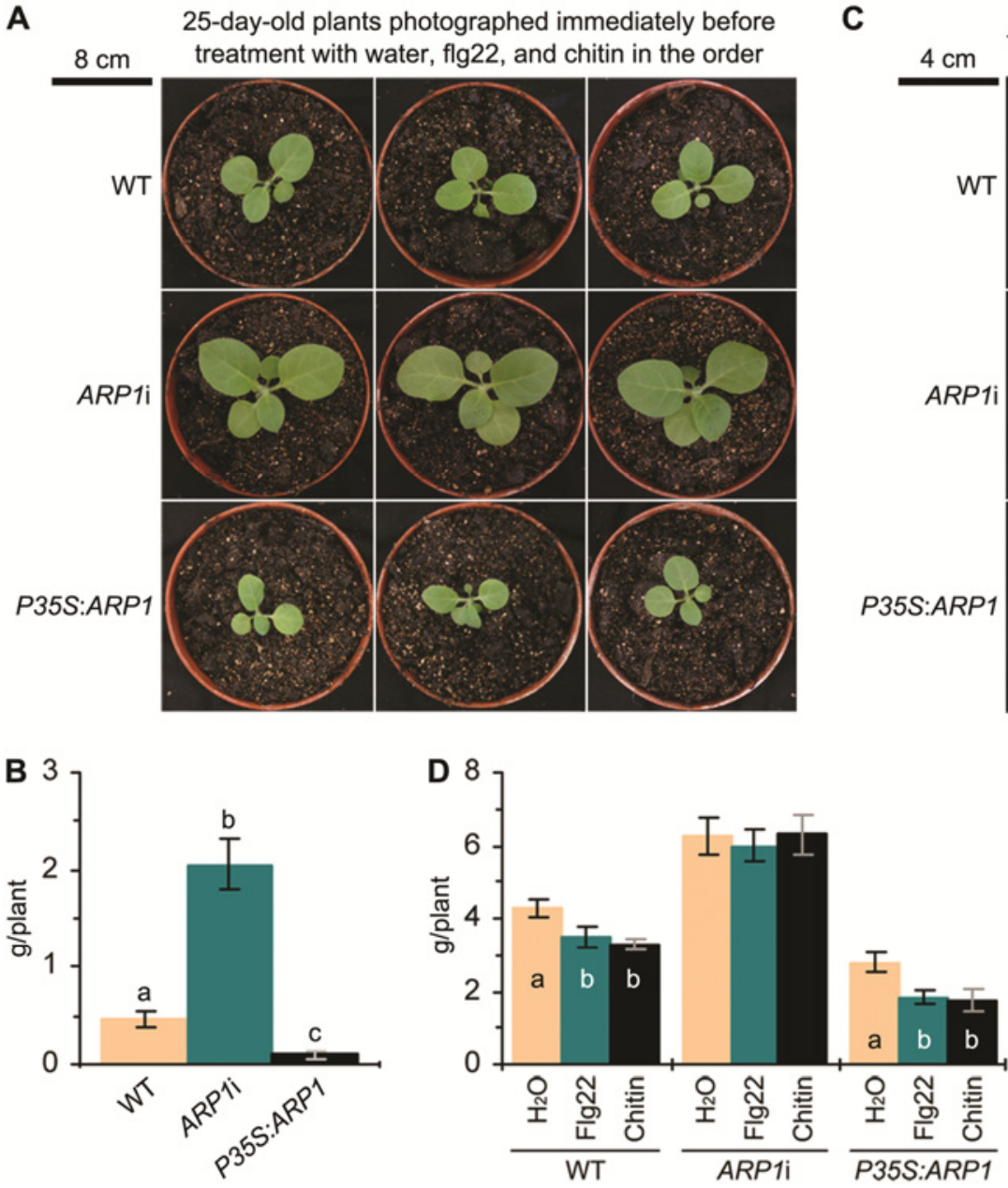

C

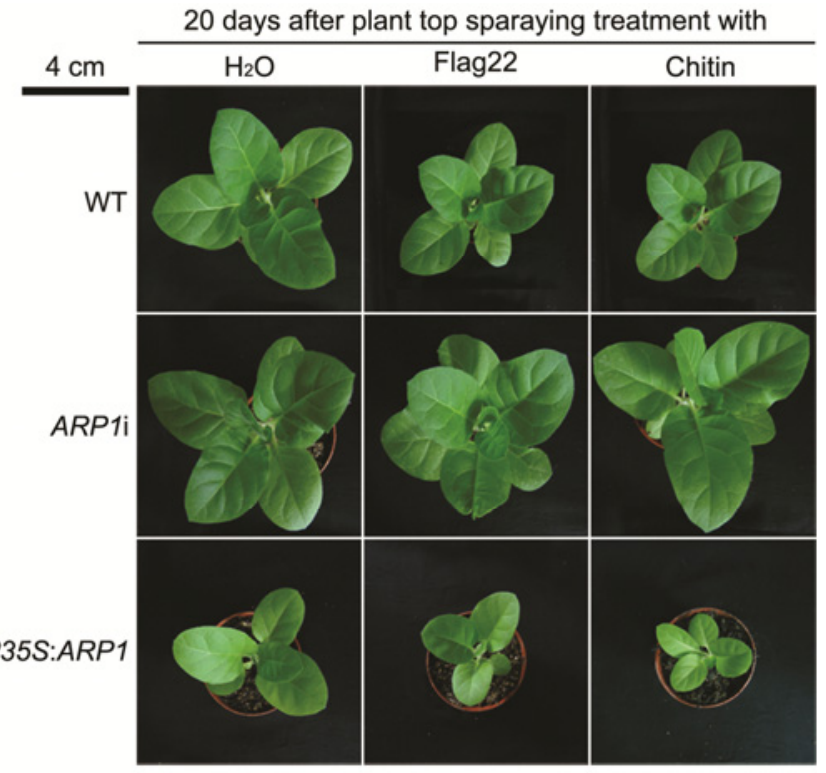

Fig. 7. Effects of flag 22 and chitin on tobacco growth. $\mathbf{A}$ and $\mathbf{B}$, Plant appearance and fresh weight quantification before treatment; WT = wild type. $\mathbf{C}$ to $\mathbf{E}$, Plant appearance and growth quantification at 25 days after treatment with flag22, chitin, or water. Data shown in bar graphs are mean values \pm standard deviation bars ( $n=3$ experimental repeats; 15 plants per repeat). Different letters in graphs indicate significant differences by one-way analysis of variance and least significant difference test $(P<0.01)$. 
elevated by $P 35 S: A R P 1$. Thus, $A R P 1$ may play a regulatory role in $A R F 8$ and $N P R 1$ expression.

To test this hypothesis, we performed PTGS to silence $A R F 8, N P R 1$, or both under of WT, ARPli, and P35S:ARP1 backgrounds. PTGS was performed on 15-day-old plants and gene-silencing effects were analyzed 7 days later (Figs. 9A and 10A). Single-gene-silenced $A R F 8 \mathrm{i}$ and NPRli plants were generated under the WT background (Fig. 9A). In $A R F 8 \mathrm{i}$, the relative unit of the $A R F 8$ transcript was $0.22,18 \%$ of the transcript unit (1.25) from the WT plant. In NPRli, the relative abundance of the NPRl transcript was $0.16,13 \%$ of the WT transcript level (1.20). Double-gene-silenced ARPli ARF8i and ARPli NPRli plants were generated under ARPli background, in which relative units of $A R F 8$ and NPRI transcripts were 6.60 and 0.15 , respectively (Fig. 9A). The ARF8 transcript level had an $82 \%(1.16 / 6.60)$ decrease in the ARPli
$A R F 8$ i plant while the NPRI transcript amount was decreased by $67 \%(0.05 / 0.15)$ in the ARPli NPRli plant. The triple-genesilenced $A R P I \mathrm{i} A R F 8 \mathrm{i} N P R l \mathrm{i}$ plant was also generated under $A R P l i$ background (Fig. 9A). In ARPli ARF8i NPRli, the $A R P 1$ silencing effect was similar to that in the ARPli ARF8i plant and the NPR1 silencing effect was similar to that in $A R P l i$ NPRli. Thus, silencing ARF8 did not affect NPRI expression, and vice versa. Moreover, silencing $A R F 8, N P R l$, or both did not affect $A R P l$ expression. Instead, $A R P I$ was expressed similarly in $A R P l i, A R P l i$ ARF 8 i, ARPli NPRli, and $A R P l i$ ARF8i NPRli plants. In these plants, however, quantities of the $A R P l$ transcript were lower than in the WT, $A R F 8 \mathrm{i}$, or NPRli plant (Fig. 9A). In addition, $A R F 8 \mathrm{i}, N P R l \mathrm{i}$, and $A R F 8 \mathrm{i} N P R l \mathrm{i}$ also performed effectively under $P 35 S: A R P 1$ background (Fig. 10A). Resulting P35S:ARP1 ARF8i, P35S: ARP1 NPRli, and P35S:ARP1 ARF8i NPRli plants were similar

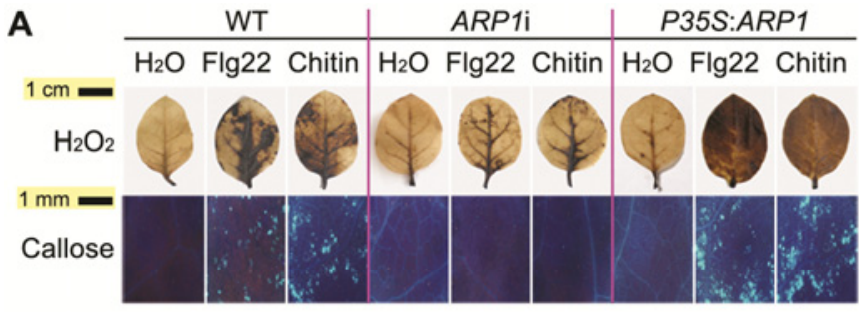

C

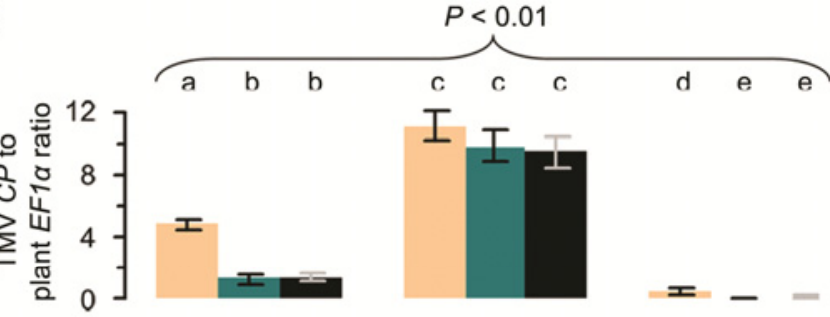

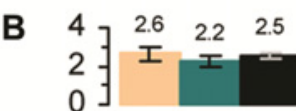
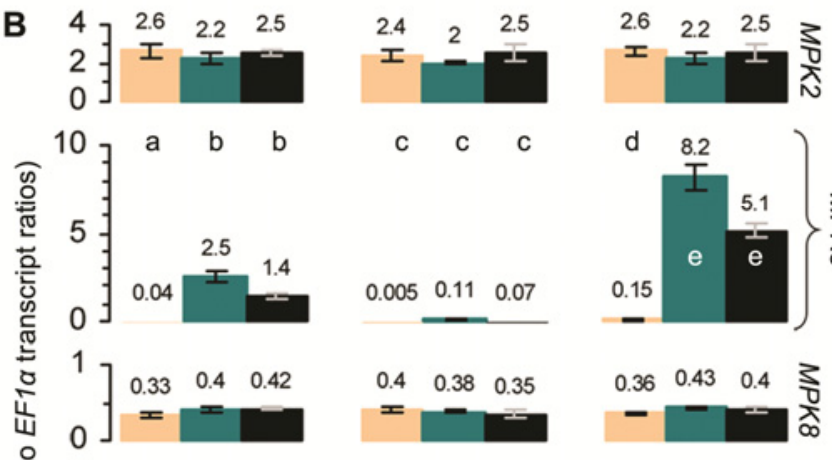

$\begin{array}{lll}0.005 & 0.11 & 0.07\end{array}$
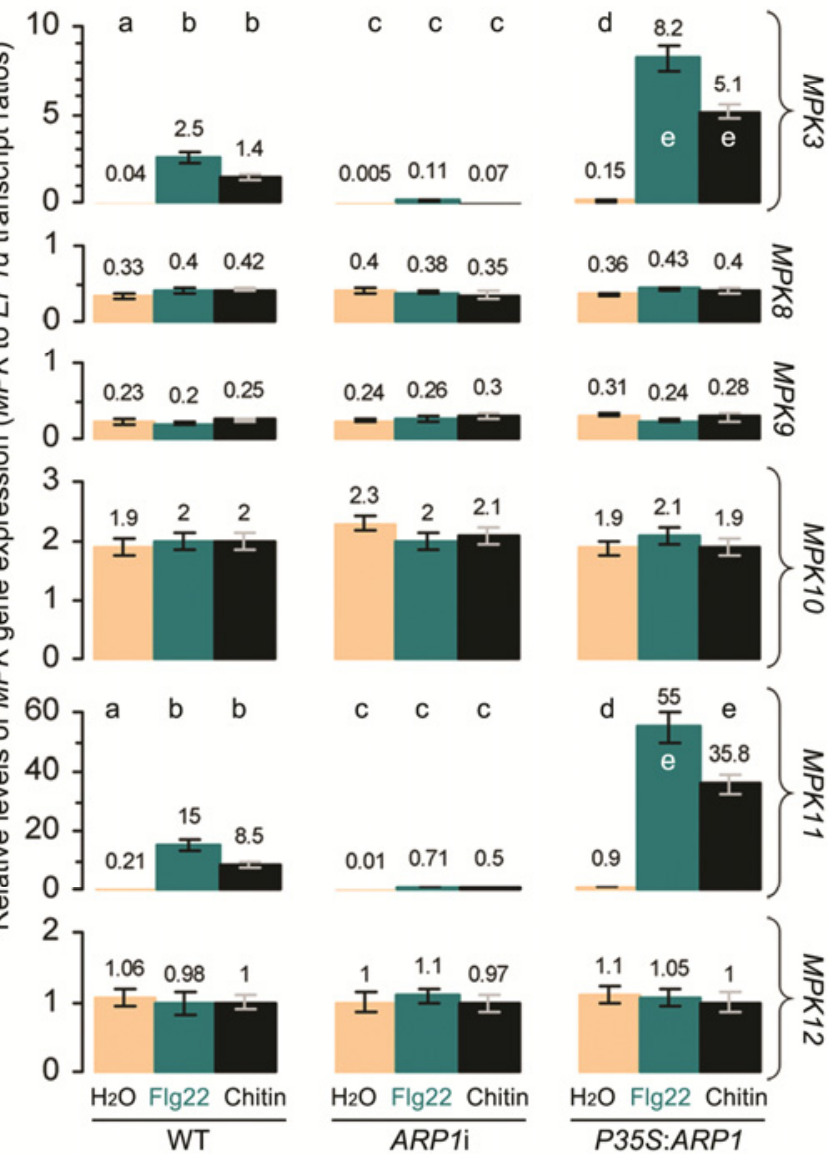
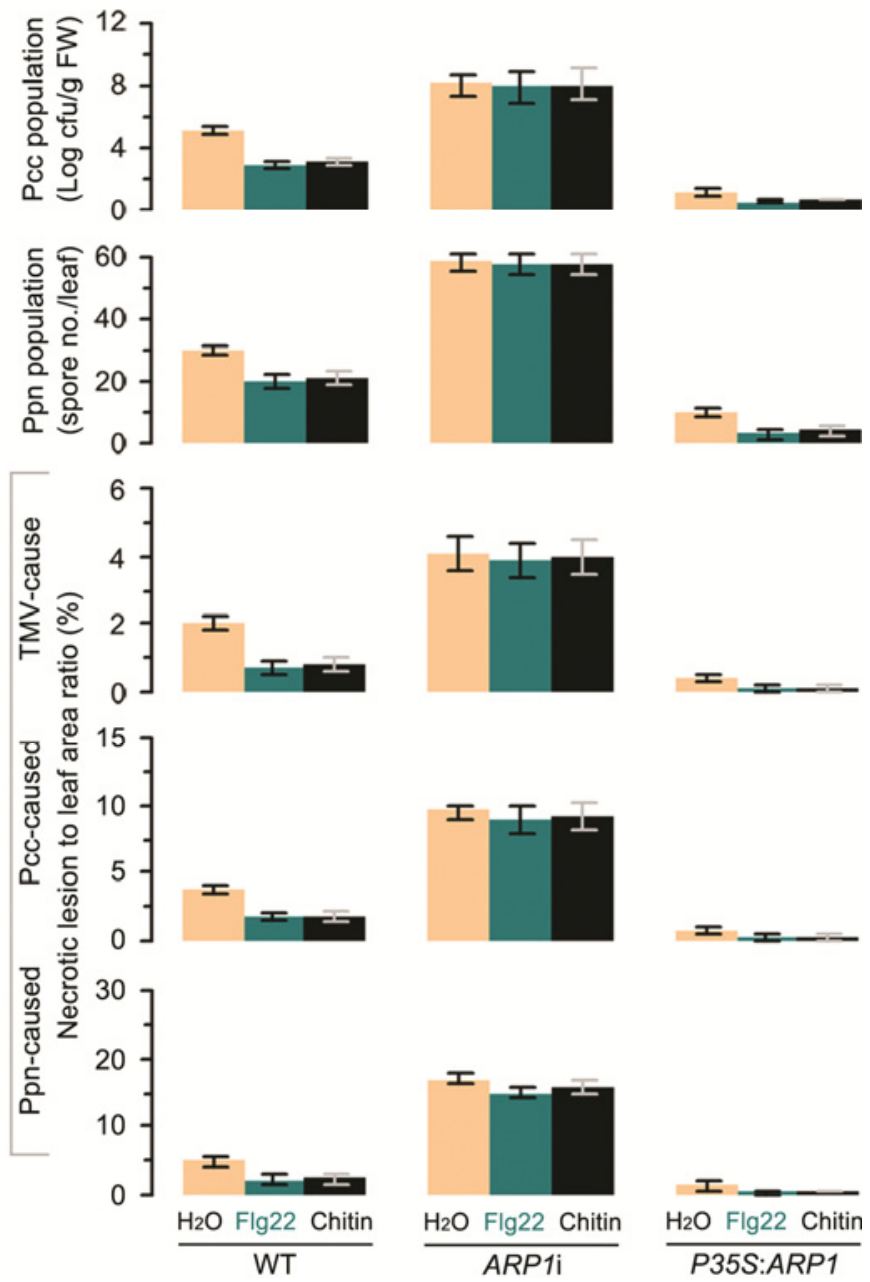

Fig. 8. Pathogen-associated molecular pattern-triggered immunity responses and pathogen infection in tobacco plants following treatment with the indicated compounds that were applied to plants. $\mathbf{A}$ and $\mathbf{B}$, The $\mathrm{H}_{2} \mathrm{O}_{2}$ production, callose deposition, and $M P K$ gene expression in in the third-youngest expanded leaves sampled at the first hour after plant treatment; WT $=$ wild type. $\mathbf{C}$, Assessments of plant infection by the three pathogens. Plants were inoculated at 5 days after treatment, pathogen growth was quantified 3 days later, and the symptom severities were scored after an additional 2 days. B and $\mathbf{C}$, Data shown are mean values \pm standard deviation bars $(n=3$ experimental repeats; 15 plants per repeat). Different letters in bar graphs (B) and on the top bar graphs $(\mathrm{C})$ indicate significant differences by one-way analysis of variance and least significant difference test $(P<0.01)$. 
in their constitutive $A R P 1$ expression, $A R F 8$ expression impairment, and NPRI expression enhancement (Fig. 10A). These analyses suggest that $A R P 1$ modulates the expression of $A R F 8$ and $N P R l$ but neither $A R F 8$ nor NPRI affects $A R P I$ expression.

\section{$A R P 1$ recruits $A R F 8$ and $N P R 1$}

\section{to coregulate growth and resistance.}

To disclose functional relationships among $A R P 1, A R F 8$, and $N P R 1$, we analyzed the effects of $A R F 8$ and NPR1 silencing on plant growth and disease resistance under WT, $A R P l \mathrm{i}$, and P35S:ARP1 backgrounds. Fresh weight of 30-day-old plants (15 days after gene silencing performances) was measured. In comparisons of different plants, significantly $(P<0.01)$ increased or decreased fresh weight was regarded as growth enhancement or repression, respectively. According to this standard, $A R F 8 \mathrm{i}$ represses plant growth but NPRli enhances growth under backgrounds of the WT or P35S:ARP1 but not ARPli (Figs. 9B and 10B). In the independent experiments, 30-dayold plants were inoculated with TMV, Pectobacterium caroto- vorum subsp. carotovora, or Phytophthora parasitica var. nicotianae. Plant infection was evaluated by assessing pathogen populations and disease severities at 5 days after inoculation. In comparisons of different plants, significantly $(P<0.01)$ reduced or aggravated infection was regarded as resistance enhancement or compromise, respectively. According to this criterion, $A R F 8 \mathrm{i}$ enhances resistance while NPRli represses resistance under background of WT or P35S:ARP1 but not ARPli (Figs. 9C and 10C). For both growth and resistance, $A R F 8$ and NPRI are antagonistic because P35S:ARPI ARF8i NPRli and P35S:ARPI plants are similar in growth and resistance extents (Figs. 9B and $\mathrm{C}$ and $10 \mathrm{~B}$ and $\mathrm{C}$ ). In addition, pathogen multiplications are facilitated by transient expression of $A R F 8$ but repressed by transient expression of NPRI under background of WT or P35S:ARPl but not ARPli (Supplementary Fig. S9). Taken together, these analyses suggest that the dual role of $A R P 1$ in plant growth and disease resistance is attributable to the antagonistic crosstalk between $A R F 8$ and NPRI.

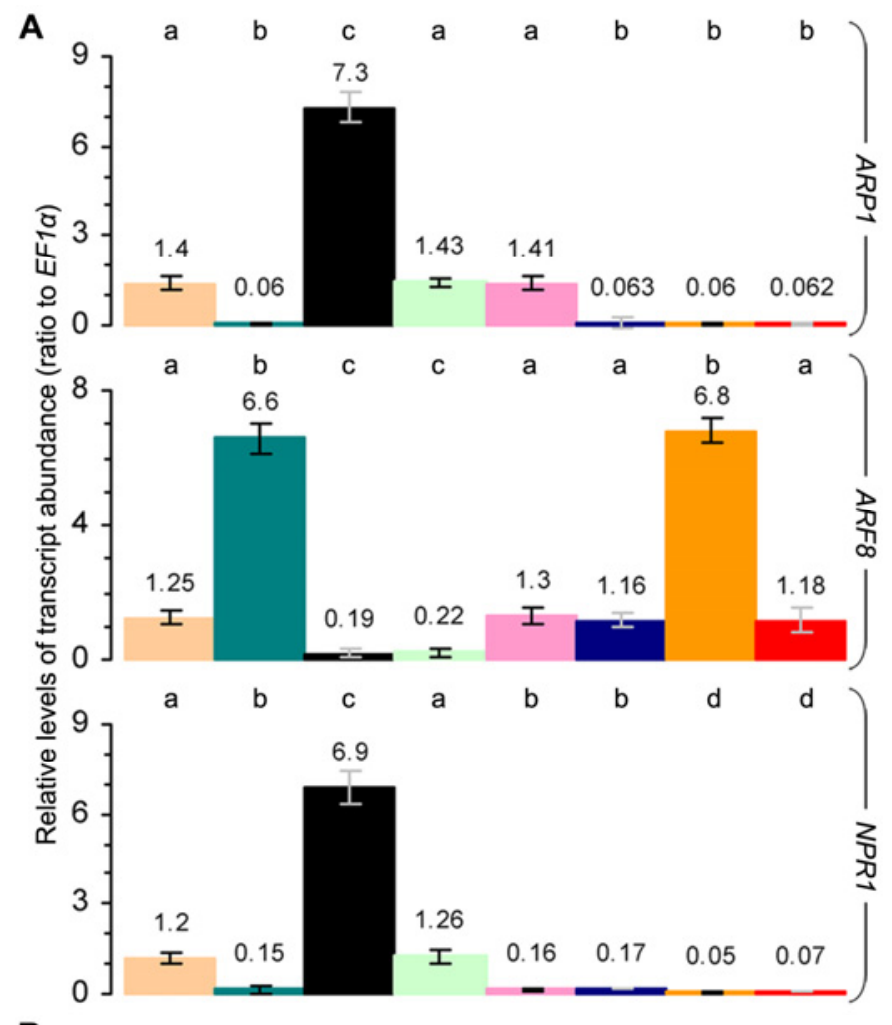

C
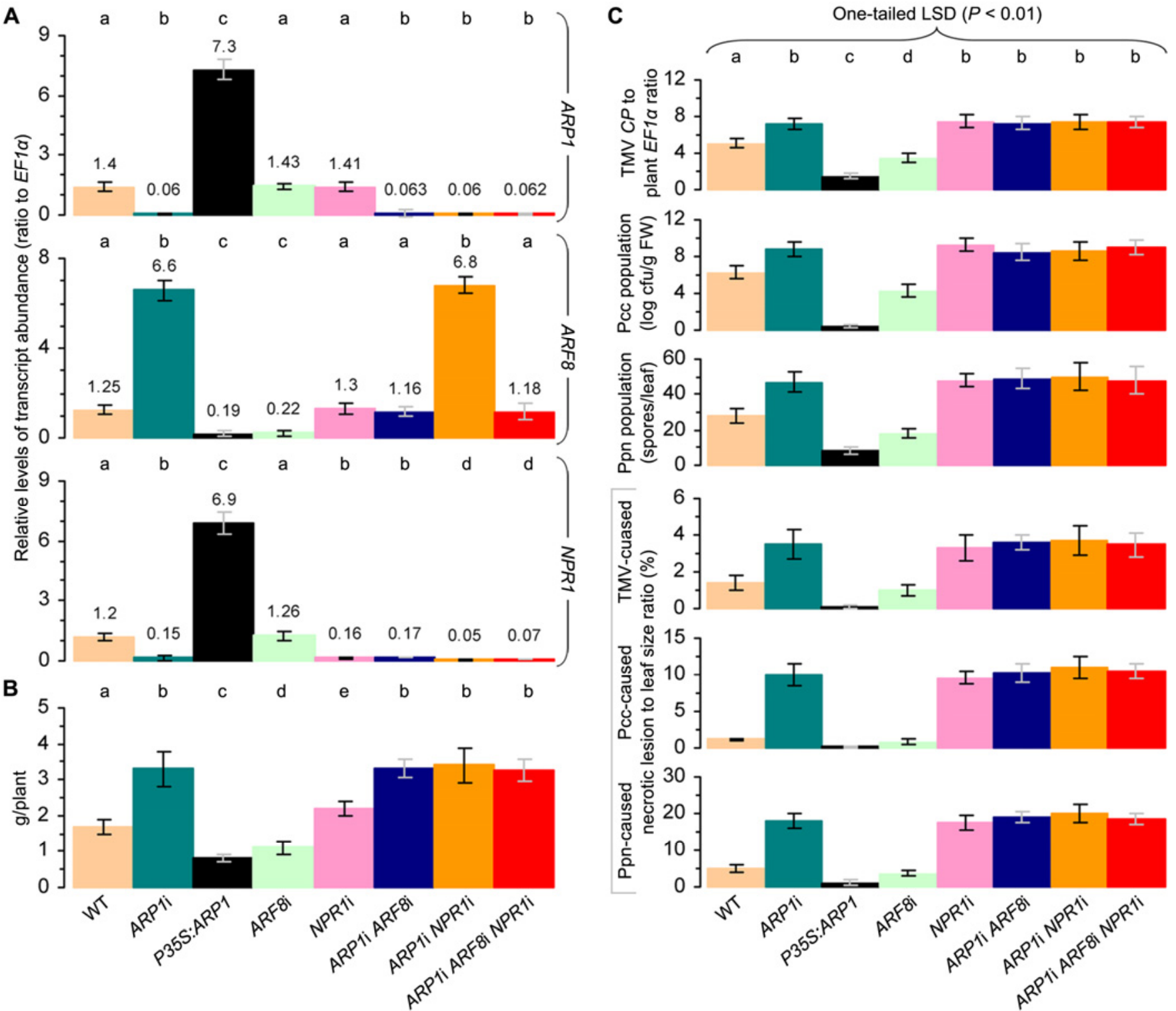

Fig. 9. Effects of $A R F 8$ and NPR1 silencing under wild-type (WT) and $A R P l i$ backgrounds on the dual role of $A R P 1$ in tobacco growth and pathogen infection. A, Gene expression in leaves at 7 days after $A R F 8$ and $N P R 1$ silencing experiments performed on 15-day-old WT or ARPli plants. B, Fresh weight of 30-day-old plants. C, Pathogen growth and symptom severities in leaves at 3 and 5 days, respectively, after ARF8 and NPR1 silencing experiments. A to C, Data shown are mean values \pm standard deviation bars $(n=3$ experimental repeats; 15 plants per repeat). Different letters in bar graphs indicate significant differences by analysis of variance and least significant difference test $(P<0.01)$. 


\section{DISCUSSION}

Modulation of signaling crosstalk is a common strategy that plants utilize to balance growth and disease resistance (Denancé et al. 2013; Deng et al. 2011; Torres 2010; Truman et al. 2010; Zhu et al. 2013). However, the molecular mechanisms that govern the crosstalk signaling networks are largely unknown (Denancé et al. 2013; Han et al. 2013; Li et al. 2012). It is also unknown how particular crosstalk signaling partners balance plant growth and disease resistance (Han et al. 2013). For instance, auxin-SA crosstalk has been shown to play an important role in regulating disease resistance (Wang et al. 2007) but how the crosstalk affects plant growth is little understood. It is believed that many components are recruited into the signaling crosstalk to balance plant growth and disease resistance (Denancé et al. 2013; Han et al. 2013; Li et al. 2012; Liu and Hu 2013; Wang et al. 2009).
This study was attempted to identify previously unappreciated regulators for plant growth and disease resistance crosstalk. By performing T-DNA-mediated insertional mutagenesis on the tobacco genome, we have isolated the plant mutants with alterations in both vegetative growth and resistance to pathogens (viruses, bacteria, and oomycetes). The geril mutant seems to be desired for our study purpose since the mutant acquires outstanding levels of growth enhancement and disease resistance impairment (Figs. 1 and 2; Table 1). In geri1, vegetative growth is enhanced with a molecular basis shown as increased expression of EXP genes (Fig. 1), which encode the expansin proteins required for the growth of plant cells and vegetative organs of plants (Chen et al. 2008; Cox et al. 2004; Sloan et al. 2009). Meanwhile, geril is also an SAR-nullified mutant because it not only is compromised in disease resistance but also fails to display pathogen-induced expression of
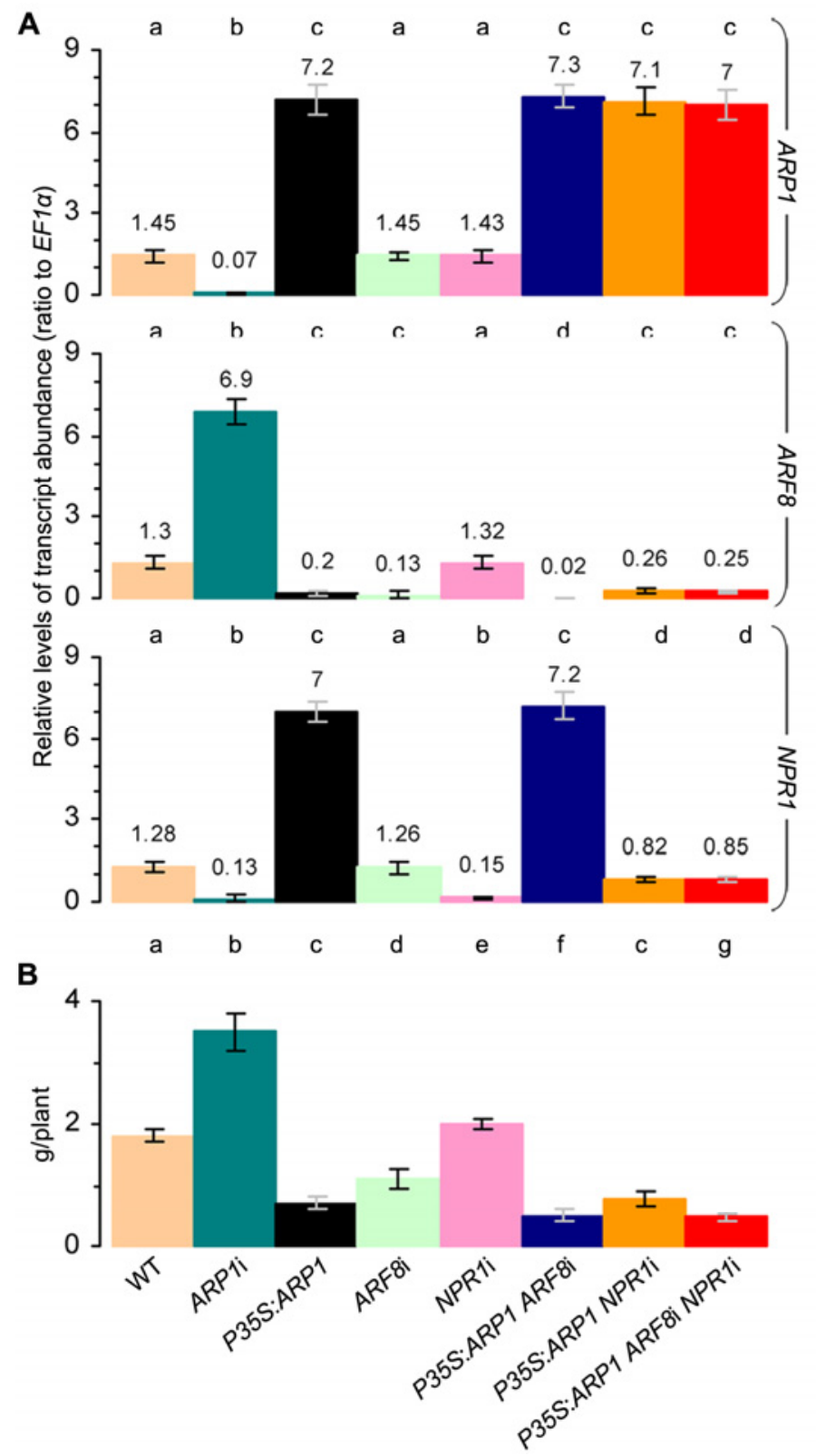

C
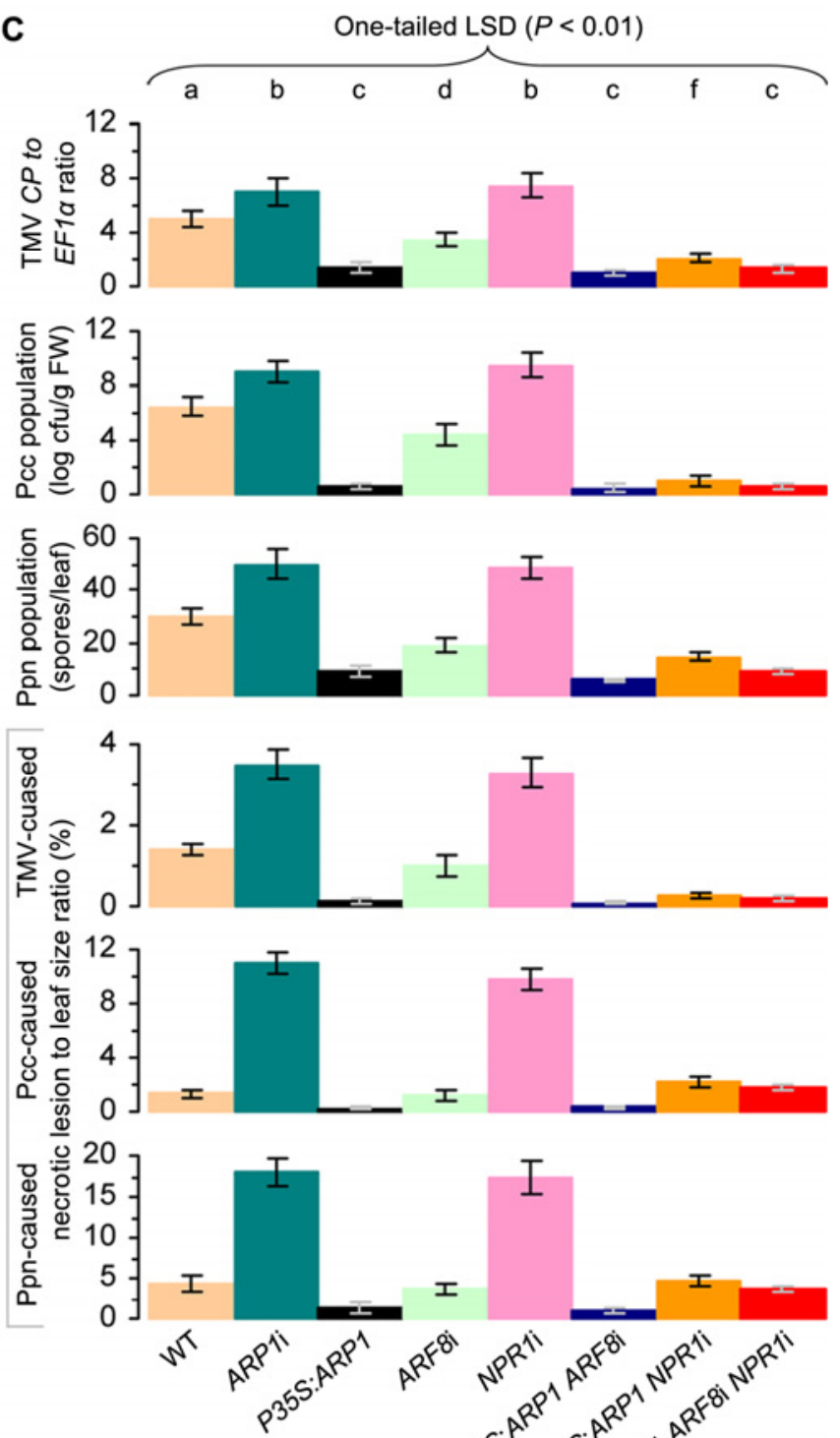

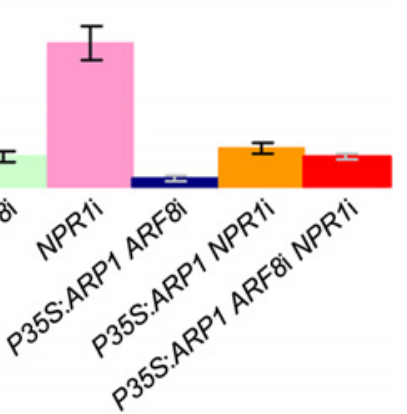

Fig. 10. Effects of $A R F 8$ and NPR1 silencing under wild-type (WT) and P35S:ARP1 backgrounds on the dual role of $A R P 1$ in tobacco growth and pathogen infection. A, Gene expression in leaves at 7 days after $A R F 8$ and NPR1 silencing experiments performed on 15-day-old WT or P35S:ARP1 plants. B, Fresh weight of 30-day-old plants. C, Pathogen growth and symptom severities in leaves at 3 and 5 days, respectively, after ARF8 and NPR1 silencing experiments. A to $\mathbf{C}$, Data shown are mean values \pm standard deviation bars $(n=3$ experimental repeats; 15 plants per repeat). Different letters in bar graphs indicate significant differences by analysis of variance and least significant difference test $(P<0.01)$. 
$P R$ genes, which are molecular markers of SAR or the NPR1regulated defense response (Cao et al. 1994; Delany et al. 1995; Dong et al. 1999; Ryals et al. 1996).

With Mendel's law of inheritance, we have elucidated the genetic characteristics of the geril mutation and isolated the WT GERII gene. Based on the WT/mutant phenotype ratios in $\mathrm{F} 1$ and $\mathrm{F} 2$ progenies from the geril $\times \mathrm{WT}$ backcross, the geril allele isolated is recessive and identifies a single genetic locus (Fig. 3; Table 2). This locus obviously contains the hypothetic GERI1 gene with T-DNA-indexed sequence (Fig. 3). On this basis, we isolated the WT GERII gene by combined use of the TAIL and RACE techniques (Fig. 3). The cloned gene contains 375 nucleotides (Fig. 3), is repressed by auxin at the transcription level, and encodes the predicted ARP1 protein (Fig. 4), which has a molecular mass of $13.5 \mathrm{kDa}$.

With the paucity of information on biological functions of ARF in plants, we have performed bioinformatics and experimental analyses on the identified tobacco ARP1 protein. According to bioinformatics analyses, ARP1 is a member of the phylogenic ARP protein family in plants and contains several functional motifs implicated in plant signal transduction and disease resistance (Lee et al. 2013) (Fig. 4). However, functions of almost all ARP identified thus far have not been characterized, except for a recent demonstration that the Brassica rapa ARP1 is a negative regulator of the vegetative growth and seed production (Lee et al. 2013). Based on the phenotype of geril (Figs. 1 and 2) and the effects of ARPI silencing, overexpression (Figs. 5 and 6), and the genetic complementation, ARPI indeed plays a dual role in the plant, negatively regulating the vegetative growth and positively regulating disease resistance. The dual role of $A R P 1$, its property as an auxin-repressed gene, and the characteristics of ARP as auxin-repressed proteins all suggest that ARP1 is a critical component by which the auxinsignaling pathway modulates crosstalk between plant growth and disease resistance.

The auxin-signaling pathway mainly comprises auxin perception by the receptor TIR1 and the subsequent activation of the $26 \mathrm{~S}$ proteasome to hydrolyze transcription repressors of the AUX/IAA protein family and release ARF transcription factors, which acts, in turn, to regulate transcription of auxin-responsive genes (Gray et al. 2001; Liscum and Reed 2002; Ulmasov et al. 1995). This pathway has been almost exclusively elucidated for the regulation of plant growth and development (Ghanashyam and Jain 2009; Han et al. 2013; Müller and Sheen 2008; Navarro et al. 2006; Shin et al. 2007). In contrast, information on the role of auxin signaling in disease resistance has been in paucity until recent years (Han et al. 2013; Lee et al. 2013; Wang et al. 2007). The role of ARP1 in crosstalk between plant growth and disease resistance suggests that the crosstalk involves more regulators of auxin signaling, in addition to TIR1, AXU/IAA, and TTG2 recently identified as regulators of disease resistance in addition to their primary roles in plant growth and development (Han et al. 2013; Li et al. 2012; Wang et al. 2007).

In support of this notion, we have elucidated that the dual role of ARP1 resembles that of PAMPs (flag22 and chitin) in repressing plant growth and activating PTI responses (Figs. 7 and 8). In essence, ARPI is required for the PAMPs and assembles the PAMPs to repress plant growth (Fig. 7). This finding relates PAMP-repressed growth to auxin responses in the plant because $A R P 1$ is an auxin-repressed gene. Meanwhile, $A R P 1$ actually functions through PTI responses to regulate disease resistance (Fig. 8). On one hand, the enhancement of disease resistance is attributable to the activation of PTI responses in the case of the ARPl gene overexpression. On the other hand, disease resistance is compromised due to arrested PTI responses when the ARPli gene is silenced. This analysis well relates $A R P 1$-repressed disease resistance to the repression of
PTI responses, which otherwise are induced as a result of plant sensing of PAMPs (Asai et al. 2002; Ausubel 2005; Zipfel et al. 2004). Therefore, we assume that ARP1 may execute its dual role in plant growth and disease resistance by modulating perception of involved signaling molecules and subsequent signal transduction in the plant.

This hypothesis has been partially validated by the epistasis analysis performed in this study to dissect the effects of $A R F 8$ and NPRI on the dual role of ARPI in tobacco growth and disease resistance (Figs. 9 and 10). Recently, we showed that the expression of $A R F 8$ in tobacco was highly dependent on TTG2 (Zhu et al. 2013), one of the TTG proteins that contains the protein-interaction WD-40 domain implicated in protein-protein interactions and regulation of plant growth, development, and defense responses (Bouyer et al. 2008; Li et al. 2012; Pang et al. 2009; Wang et al. 2009). The TTG2-dependent expression of $A R F 8$ is highly correlated with TTG2-regulated growth and development in tobacco (Zhu et al. 2013). By contrast, TTG2 suppresses disease resistance of the plant by retaining the NPR1 protein in the cytoplasm, sequestering NPR1 from the nucleus, and preventing its regulatory role in $P R$ gene expression ( $\mathrm{Li}$ et al. 2012). In the present study, results obtained from the epistasis analysis elucidate the functional relationships among $A R P 1, A R F 8$, and NPRI. ARP1 is required for the expression of $N P R 1$ and is repressive to the expression of $A R F 8$, whereas neither NPRI nor ARF8 affects ARPl expression (Figs. 9 and 10). This suggests that $A R P l$ acts upstream of $A R F 8$ and NPR1 in the gene expression process. Moreover, $A R P 1$ represses plant growth and confers disease resistance through antagonistic crosstalk between ARF8 and NPRI (Figs. 9 and 10). This indicates that the dual role of ARP1 in plant growth and disease resistance is related to transcriptional regulation of auxin-signaling and SA-signaling pathways by ARF8 (Zhu et al. 2013) and NPR1 (An and Mou 2011; Cao et al. 1997; Mukhtar et al. 2009), respectively.

In summary, multiple lines of evidence obtained from genetic and molecular analyses performed in this study strongly suggest that ARP1 is an integral regulator for crosstalk between growth and disease resistance in the plant. The dual role of ARP1 may be implicated in plant-pathogen interactions and plant innate immunity because ARP1 resembles PAMPs and is required for them to induce PTI responses and repress plant growth. Furthermore, evidence obtained from the epistasis analysis indicates that the dual role of $A R P 1$ is executed by antagonistic crosstalk between $A R F 8$ and NPRI. However, it is a great challenge to characterize whether ARP1 also modulates plant sensing of the auxin and SA signals. Plants recognize the auxin signal through the receptor TIR1 (Hayashi 2012; Quint and Gray 2006; Strader and Nemhauser 2013), whereas the SA repression of TIR1 is an integral component of the NPR1-regulated defense (Denancé et al. 2013; Wang et al. 2007). Plants sense the SA signal via the receptor protein NPR3 or NPR4 (Fu et al. 2012) but there is, as yet, no study to show whether auxin regulates plant growth (Quint and Gray 2006; Vanneste and Friml 2009) by affecting the role of NPR3 or NPR4 in sensing of SA (Fu et al. 2012; Kaltdorf and Naseem 2013). Characterization of functional relationships among these regulators in crosstalk to balance plant growth and disease resistance will be the subject of further studies. In particular, it is great of interest to study in the future whether ARP1 plays a role in plant sensing of the SA and auxin signals through the corresponding receptor proteins.

\section{MATERIALS AND METHODS}

\section{Plant growth.}

Tobacco genotypes tested in this study were $N$. tabacum Xanthi (NN) and its geril mutant, $A R P l$-silenced line 
$A R P 1$ RNAi, and ARPl-overexpressing line P35S::ARPl generated in this study. Germinating seed (Ren et al. 2008) were grown on MS agar medium with or without kanamycin at 150 $\mu \mathrm{g} / \mathrm{ml}$ in scaled square plastic plates. After sowing, the plates were incubated in an environment-controlled chamber at 23 to $25^{\circ} \mathrm{C}, 55 \pm 2 \%$ humidity, a circle of $10 \mathrm{~h}$ of light and $14 \mathrm{~h}$ of darkness, and light at $250 \mu \mathrm{E} / \mathrm{m}^{2} / \mathrm{s}$. The length of roots on the medium was monitored. Alternatively, seed were sown directly in potting soil (Dong et al. 2004) in $15-\mathrm{cm}$ pots and incubated in the greenhouse at 22 to $26^{\circ} \mathrm{C}$ under a natural photoperiod cycle. Plant growth extents were observed, fresh weight was determined, and life size was measured with the Li-3100C system (LI-COR, Inc., Lincoln, NE, U.S.A.).

\section{Mutant screening.}

The $p B I 121$ vector that contains the NPTII gene encoding kanamycin resistance as a selective marker was transferred into the WT tobacco genome under mediation by Agrobacterium tumefaciens (Peng et al. 2004). Transgenic lines were screened by conventional approaches (Liu et al. 2011; Peng et al. 2004). Homozygous T3 progenies were used in evaluations of growth and disease resistance. The geril mutant plants were backcrossed to the WT plant by pollinating the WT with mutant pollens. Backcross progenies were analyzed for Mendelian ratios based on $\chi^{2}$ test, as previously described (Delaney et al. 1995; Ma et al. 1979).

\section{Gene expression analysis.}

Total RNA was isolated from the third-youngest leaves of tobacco plants grown in pots and subjected to reverse-transcriptase (RT)-PCR or real-time RT-PCR using the constitutively expressed EF1 $\alpha$ or Actin 2 gene as a reference. Firststrand cDNA was synthesized from $2 \mu \mathrm{g}$ of RNA using the superscript II RNAse $\mathrm{H}^{-}$Reverse Transcriptase (Invitrogen, Carlsbad, CA, U.S.A.) and specific primers. Reaction treatments, RT-PCR protocols, product cloning, and sequencing verification were as previously described (Chen et al. 2008). Products were resolved by agarose gel electrophoresis and visualized by staining with ethidium bromide. An established quantitative method (Livak and Schmittgen 2001) was used in real-time RT-PCR analyses. Genes were amplified $<26$ cycles, with a range of template concentration increases by $0.5 \mathrm{ng}$ and from 0 to $3.0 \mathrm{ng}$ in $25-\mu \mathrm{l}$ reaction solutions to select desired doses. All reactions were performed in triplicate with null-template controls in which cDNA was absent. Relative level of a tested gene was quantified as the gene/EFl $\alpha$ transcript ratio (Chen et al. 2008; Liu et al. 2011).

\section{Plant inoculation and infection assessments.}

TMV, Pectobacterium carotovorum subsp. carotovora, and Phytophthora parasitica var. nicotianae were inoculated to the third-youngest leaves of plants grown in pots. Inoculants of TMV and Pectobacterium carotovorum subsp. carotovora were prepared and inoculation was performed as described by Dong and Beer (2000) and Wu and associates (2010), respectively. The population of $P$. carotovorum subsp. carotovora propagated (Wu et al. 2010) and the transcript amount of TMV $C P$ gene expressed ( $\mathrm{Li}$ et al. 2012) in the inoculated leaves were determined at intervals for $72 \mathrm{~h}$ after inoculation. The expression of TMV CP gene was determined as for a plant gene using the method stated above. To prepare the Phytophthora parasitica var. nicotianae inoculum, sporangiospores were produced from a culture on potato extract dextrose agar medium, prepared as a suspension of $5 \times 10^{6}$ spores $/ \mathrm{ml}$, and this suspension was infiltrated into leaf intercellular spaces. Infiltrated leaves were excised and incubated on wet filter papers in 9-cm petri-dishes at $25^{\circ} \mathrm{C}$ for 3 to 5 days. Within this period, sporangiospores were able to be collected any time by cutting the leaves and immersing them in sterile water. During this inoculum preparation process, all operations and materials were kept in disinfected conditions. Amounts of sporangiospores collected in sterile water were quantified by microscopic observation on a 5- $\mu$ l sample. Sporangiospore amounts were adjusted to $1 \times 10^{6}$ spores $/ \mathrm{ml}$ in the suspension and this suspension was inoculated to leaves on plants by infiltrating leaf intercellular spaces. At intervals for $72 \mathrm{~h}$ after inoculation, populations of sporangiospores produced in inoculated leaves were determined by the method used for the inoculum collection. In all inoculation experiments, leaf chlorosis or necrosis symptoms caused by the pathogens were observed 5 days after inoculation. Symptom severities were quantified as chlorosis or necrosis area/leaf size ratios, as previously described ( $\mathrm{Wu}$ et al. 2010).

\section{TAIL and RACE PCR.}

The TAIL-PCR technique (Huang et al. 2010) was performed to amplify the T-DNA-flanking sequence in geril genomic DNA by using three T-DNA-specific primers (TP1 to TP3) and six arbitrary degenerate primers (ADP1 to ADP6) (Supplementary Table S2). TP1, TP2, and TP3 were designed according to the 200-bp 5'-3' sequence adjacent to the right border of the T-DNA insert. The distance was 39 nucleotides between TP1 and TP2 and 86 nucleotides between TP2 and TP3. TAIL PCR was accomplished by three rounds of reaction (Supplementary Table S3) and elaborately designed protocols (Supplementary Table S4). In the first-round reaction, ADP1 to ADP6 were mixed with TP1 and the mixture was used for the TAIL PCR protocol performed with geril genomic DNA. Product was used as a template in the second-round TAIL PCR protocol performed with the mixture of TP2 and ADP1 to ADP6. Product was used as a template in the final-round TAIL PCR protocol performed with the mixture of TP3 and ADP1 to ADP6. Product from this final TAIL PCR was cloned into the pMD 19-T Simple Vector (TaKaRa Biotech. Co., Ltd., China Branch, Dalian, China), followed by transformation of the Escherichia coli DH5 $\alpha$ cells. Recombinant DH5 $\alpha$ cells were used for sequencing and the sequence was annotated by Blast searches against the NCBI databases.

The specific primer used in the 3 -RACE PCR was synthesized according to the annotated sequence from the final TAIL PCR protocol. The primer was mixed with the 3 '-terminal polyA primer and the mixture was used in RT-PCR performed with total RNA isolated from leaves of the WT tobacco plant. The product was sequenced and sequence was analyzed.

\section{Bioinformatics analysis.}

Online programs were used. Sequences were compared and aligned by the Blast search and DNAssist programs, respectively. A phylogenetic tree was generated with the Blast search program. Both DNAStar and DNAMAN were used to recognize the TAIL PCR part and the RACE-expanded part of the gene and to identify the intact ORF. Protein molecular mass was predicted with the DNAStar program.

\section{Gene-silencing experiments.}

The PTGS system mediated by the disarmed strain Y35 of Tobacco curly shoot virus (Li et al. 2012; Qian et al. 2006; Sun et al. 2010; Wang et al. 2009) was used to silence $A R P 1$ under WT background and to silence $A R F 8, N P R 1$, or both under WT, ARPli, and P35S:ARPl backgrounds. Vectors pBinPlusY35 DNA1:2mß and pBinPlus:Y35 DNA-A, functioning for gene silencing effect and transformation assistance (Tao and Zhou 2004), were provided by Dr. X.-P. Zhou (Biotechnology Institute, Zhejiang University, Hangzhou, China). Coding se- 
quences (cDNAs) of full-length ARP1 (269 bp), a 607-bp $A R F 8$ fragment, and a 536-bp NPRI fragment (Li et al. 2012) were obtained by RT-PCR with WT RNA and specific primers amended at $5^{\prime}$ termini with bases for BamHI and $\mathrm{XbaI}$ restrictions. RT-PCR products were confirmed by sequencing and cloned separately into pBinPlus-Y35 DNA1:2m $\beta$ (Tao and Zhou 2004), creating the gene silencing units pBinPlus-Y35

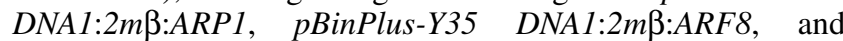
pBinPlus-Y35 DNA1:2mß:NPR1. Each unit was transferred into Agrobacterium tumefaciens EHA105 cells. EHA105 cells were also transformed with pBinPlus:Y35 DNA-A. Both types of recombinant EHA105 cells were cultured, their suspensions were mixed with equal volume, and the mixture was infiltrated into emerging heart leaves of 15-day-old tobacco plants ( $\mathrm{Li}$ et al. 2012; Sun et al. 2010; Wang et al. 2009). In the experimental control group, plants were infiltrated with a mixture made of EHA105 cells containing the empty pBinPlus-Y35 $D N A 1: 2 m \beta$ vector and EHA105 cells containing the helper vector $p B i n P l u s: Y 35$ DNA-A. Seven days later, gene-silencing efficiency was evaluated by RT-PCR and real-time RT-PCR analyses using total RNA isolated from newly growing top leaves of transformed plants and control plants. The same RNA samples were used for analyses of $P R$ and EXP expression. At 15 days after transformation, the third-youngest leaves were inoculated with TMV, Pectobacterium carotovorum subsp. carotovora, and Phytophthora parasitica var. nicotianae, respectively. Infection was assessed as stated above. In addition, plant growth was monitored. These analyses were performed on plants in the independent experiments.

\section{Gene overexpression experiments.}

The ARPI overexpression unit was constructed by cloning full-length cDNA of the gene into the plant binary vector pCAMBIA1301 (CAMBIA, Brisbane, Australia) at the 3'-terminal end of $P 35 S$. The recombinant vector $p C A M B I A 1301$ : $P 35 S: A R P 1$ was transferred into the WT tobacco genome by leaf disc immersion with a suspension of recombinant $A$. tumefaciens EHA105 cells (Liu et al. 2011). Transgenic lines were generated, screened, and characterized by conventional methods (Liu et al. 2011; Peng et al. 2004). Homozygous T3 progenies of P35S:ARP1 plants were further investigated. Growth and disease resistance were assessed as stated above.

\section{Analyses of plant responses to PAMPs.}

A $1-\mu \mathrm{M}$ aqueous solution of flg22 (Absin Biosci, Inc., Shanghai, China) and a $100 \mu \mathrm{g} / \mathrm{ml}$ aqueous suspension of chitin (Sigma-Aldrich Co., St. Louis) were amended with the surfactant Silwet-37 (Sigma-Aldrich Co.) to 25-day-old plants by spraying over plant tops. Pure water was applied similarly as a control. One hour later, the $\mathrm{H}_{2} \mathrm{O}_{2}$ production (Chen et al. 2008; Deng et al. 2011), callose deposition (Lü et al. 2013), and transcripts of $M P K$ genes in the third-youngest expanded leaves were analyzed. At 20 days after treatment, fresh weight of 45-day-old plants was scored. In the independent experimental group, the third-youngest expanded leaves of equivalent plants were inoculated with TMV, Pectobacterium carotovorum subsp. carotovora, and Phytophthora parasitica var. nicotianae, respectively, at day five after treatment. Three days later, pathogen populations (TMV CP expression, Pectobacterium carotovorum subsp. carotovora CFU, and Phytophthora parasitica var. nicotianae spores) were determined. After an additional 2 days, symptom severities were evaluated.

\section{Transinfection experiments.}

Full-length cDNAs of ARF8 (843 bp) and NPR1 (1,767 bp) were obtained by RT-PCR using WT RNA and specific primers. Confirmed sequences were cloned into the plant binary vector, generating recombinant vectors $p C A M B I A 1301: 35 S$ : $A R F 8$ and $p C A M B I A 1301: 35 S: N P R 1$, respectively. Recombinant vectors were transferred separately into A. tumefaciens EHA105 cells and the bacterial suspensions were prepared, followed by transinfection of 30-day-old WT, ARPli, and P35S:ARP1 plants. Suspensions of EHA105 with $p C A M B I A-$ 1301:35S:ARP1 and $p C A M B I A 1301: 35 S: N P R 1$ were prepared separately or mixed at an equal volume before use. Plant transinfection was performed on the third-youngest leaves by infiltrating the single or mixed EHA105 suspension into leaf intercellular spaces at two sites that were approximately symmetrical on the middle part of a leaf. Leaves were infiltrated with pure water in the experimental control group. Gene expression analyses and pathogen inoculation were performed $60 \mathrm{~h}$ later on the transinfected or infiltrated leaves. Pathogen infection was evaluated as stated above.

\section{Data analysis.}

Data presented were obtained from at least three independent experiments, each experiment included at least three biological repeats, and at least five plant individuals were tested in each repeat. Quantitative data were subjected to the analysis of variance and Fisher's least significant difference test (Lü et al. 2013).

\section{ACKNOWLEDGMENTS}

We thank X. Zou (Biotechnology Institute, Zhejiang University, Hangzhou, China) for the gift of PTGS vectors. This study was supported by grants from the national 973 Plan (2012CB114003), NSFC (31171830 and 31272072), Novel Transgenic Organisms Breeding Project (2013ZX08002001), and Ministry of Education 111 Project of China and Academic Priority Program of High Education in Jiangsu Province.

\section{LITERATURE CITED}

An, C., and Mou, Z. 2011. Salicylic acid and its function in plant immunity. J. Integr. Plant Biol. 53:412-428.

Asai, T., Tena, G., Plotnikova, J., Willmann, M. R., Chiu, W. L., GomezGomez, L., Boller, T., Ausubel, F. M., and Sheen, J. 2002. MAP kinase signalling cascade in Arabidopsis innate immunity. Nature 415:977983.

Ashtamker, C., Kiss, V., Sagi, M., Davydov, O., and Fluhr, R. 2007. Diverse subcellular locations of crytogein-induced reactive oxygen species production in tobacco bright yellow-2 cells. Plant Physiol. 143:1817-1826.

Ausubel, F. M. 2005. Are innate immune signaling pathways in plants and animals conserved? Nature Immuno.1 6:973-979.

Banks, J. A., Nishiyama, T., Hasebe, M., Bowman, J. L., Gribskov, M., dePamphilis, C., Albert, V. A., Aono, N., Aoyama, T., Ambrose, B. A., Ashton, N. W., Axtel, M. J., Barker, E., Barker, M. S., Bennetzen, J. L., Bonawitz, N. D., Chapple, C., Cheng, C., Correa, L. G. G., Dacre, M., DeBarry, J., Dreyer, I., Elias, M., Engstrom, E. M., Estelle, M., Feng, L., Finet, C., Floyd, S. K., Frommer, W. B., Fujita, T., Gramzow, L., Gutensohn, M., Harholt, J., Hattori, M., Heyl, A., Hirai, T., Hiwatashi, Y., Ishikawa, M., Iwata, M., Karol, K. G., Koehler, B., Kolukisaoglu, U., Kubo, M., Kurata, T., Lalonde, S., Li, K., Li, Y., Litt, A., Lyons, E., Manning, G., Maruyama, T., Michael, T. P., Mikami, K., Miyazaki, S., Morinaga, S.-I., Murata, T., Mueller-Roeber, B., Nelson, D. R., Obara, M., Oguri, Y., Olmstead, R. G., Onodera, N., Petersen, B. L., Pils, B., Prigge, M., Rensing, S. A., Riaño-Pachón, D. M., Roberts, A. W., Sato, Y., Scheller, H. V., Schulz, B., Schulz, C., Shakirov, E. V., Shibagaki, N., Shinohara, N., Shippen, D. E., Sørensen, I., Sotooka, R., Sugimoto, N., Sugita, M., Sumikawa, N., Tanurdzic, M., Theißen, G., Ulvskov, P., Wakazuki, S., Weng, J.-K., Willats, W. W. G. T., Wipf, D., Wolf, P. G., Yang, L., Zimmer, A. D., Zhu, Q., Mitros, T., Hellsten, U., Loqué, D., Otillar, R., Salamov, A., Schmutz, J., Shapiro, H., Lindquist, E., Lucas, S., Rokhsar, D., and Grigoriev, I. V. 2011. The Selaginella genome identifies genetic changes associated with the evolution of vascular plants. Science 332:960-963.

Bethke, G., Pecher, P., Eschen-Lippold, L., Tsuda, K., Katagiri, F., Glazebrook, J., Scheel, D., and Lee, J. 2012. Activation of the Arabidopsis thaliana mitogen-activated protein kinase MPK11 by the flagellinderived elicitor peptide, flg22. Mol. Plant-Microbe Interact. 25:471-480. 
Bouyer, D., Geier, F., Kragler, F., Schnittger, A., Pesch, M., Wester, K., Balkunde, R., Timmer, J., Fleck, C., and Hulskamp, M. 2008. Twodimensional patterning by a trapping/depletion mechanism: The role of TTG1 and GL3 in Arabidopsis trichome formation. PLoS Biol. 6:11661177. Published online.

Cao, H., Glazebrook, J., Clarke, J. D., Volko, S., and Dong, X. N. 1997. The Arabidopsis NPR1 gene that controls systemic acquired resistance encodes a novel protein containing ankyrin repeats. Cell 88:57-63.

Chen, L., Qian, J., Qu, S. P., Long, J. Y., Yin, Q., Zhang, C. L., Wu, X. J., Sun, F., Wu, T. Q., Beer, S. V., and Dong, H. S. 2008. Identification of specific fragments of $\mathrm{HpaG}_{\mathrm{Xooc}}$, a harpin protein from Xanthomonas oryzae pv. oryzicola, that induce disease resistance and enhanced growth in rice. Phytopathology 98:781-791.

Cox, M. C., Benschop, J. J., Vreeburg, R. A., Wagemaker, C. A., Moritz, T., Peeters, A. J., and Voesenek, L. A. 2004. The roles of ethylene, auxin, abscisic acid, and gibberellin in the hyponastic growth of submerged Rumex palustris petioles. Plant Physiol. 136:2948-2960.

Dangl, J. L., and Jones, J. D. 2001. Plant pathogens and integrated defence responses to infection. Nature 411:826-833.

Dangl, J. L., Dietrich, R. A., and Richberg, M. H. 1996. Death don't have no mercy: Cell death programs in plant-microbe interactions. Plant Cell 8:1793-1807

Datta, S., and Muthukrishnan, S. 1999. Pathogenesis-Related Proteins in Plants. CRC Press, Boca Raton, FL, U.S.A.

Daudi, A., Cheng, Z., O'Brien, J. A., Mammarella, N., Khan, S., Ausubel, F. M., and Bolwell, G. P. 2012. The apoplastic oxidative burst peroxidase in Arabidopsis is a major component of pattern-triggered immunity. Plant Cell 24:275-287.

Delaney, T. P., Uknes, S., Vernooij, B., Friedrich, L., Weymann, K., Negrotto, D., Gaffney, T., Gut-Rella, M., Kessmann, H., Ward, E., and Ryals, J. 1994. A central role of salicylic acid in plant disease resistance. Science 266:1247-1250.

Delaney, T. P., Friedrich, L., and Ryals, J. A. 1995. Arabidopsis signal transduction mutant defective in chemically and biologically induced disease. Proc. Natl. Acad. Sci. U.S.A. 92:6602-6606.

Denancé, N., Sánchez-Vallet, A., Goffner, D., and Molina, A. 2013. Disease resistance or growth: The role of plant hormones in balancing immune responses and fitness costs. Front. Plant Sci. 4:155.

Deng, B. L., Deng, S., Sun, F., Zhang, S. J., and Dong, H. 2011. Downregulation of free riboflavin content induces hydrogen peroxide and a pathogen defense in Arabidopsis. Mol. Plant Biol. 77:185-201.

Deng, S., Yu, M., Wang, Y., Jia, Q., Lin, L., and Dong, H. 2010. The antagonistic effect of hydroxyl radical on the development of a hypersensitive response in tobacco. FEBS (Fed. Eur. Biochem. Soc.) J. 277:5097-5111.

Dong, H., and Beer, S. V. 2000. Riboflavin induces disease resistance in plants by activating a novel signal transduction pathway. Phytopathology 90:801-811.

Dong, H., Delaney, T. P., Bauer, D. W., and Beer S. V. 1999. Harpin induces disease resistance in Arabidopsis through the systemic acquired resistance pathway mediated by salicylic acid and the NIM1 gene. Plant J. 20:207-215

Dong, H. P., Peng, J. L., Bao, Z. L., Meng, X. D., Bonasera, J. M., Chen, G. Y., Beer, S. V., and Dong, H. 2004. Downstream divergence of the ethylene signaling pathway for harpin-stimulated Arabidopsis growth and insect defense. Plant Physiol. 136:3628-3638.

Eckardt, N. A. 2012. A microRNA cascade in plant defense. Plant Cell 24:840

Eliasson, L. 1969. Growth regulators in Populus tremula I. Distribution of auxin and growth inhibitors. Physiol. Plant 22:1288-1301.

Fu, Z. Q., Yan, S., Saleh, A., Wang, W., Ruble, J., Oka, N., Mohan, R., Spoel, S. H., Tada, Y., Zheng, N., and Dong, X. 2012. NPR3 and NPR4 are receptors for the immune signal salicylic acid in plants. Nature 486:228-232.

Ghanashyam, C., and Jain, M. 2009. Role of auxin-responsive genes in biotic stress responses. Plant Signal. Behav. 4:846-848.

Göhre, V., Jones, A. M., Sklenář, J., Robatzek, S., and Weber, A. P. 2012. Molecular crosstalk between PAMP-triggered immunity and photosynthesis. Mol. Plant-Microbe Interact. 25:1083-1092.

Gray, W., Kepinski, S., Rouse, D., Leyser, O., and Estelle, M. 2001. Auxin regulates $\mathrm{SCF}^{\mathrm{TIR} 1}$-dependent degradation of AUX/IAA proteins. Nature 414:271-276.

Guilfoyle, T. J., and Hagen, G. 2007. Auxin response factors. Curr. Opin. Plant Biol. 10:453-460.

Guilfoyle, T. J., Ulmasov, T., and Hagen, G. 1998. The ARF family of transcription factors and their role in plant hormone-responsive transcription. Cell Mol. Life Sci. 54:619-627.

Ha, C. V., Le, D. T., Nishiyama, R., Watanabe, Y., Sulieman, S., Tran, U. T., Mochida, K., Dong, N. V., Yamaguchi-Shinozaki, K., Shinozaki, K., and Tran, L. S. 2013. The auxin response factor transcription factor family in soybean: Genome-wide identification and expression analyses during development and water stress. DNA Res. 20:511-524.

Hagen, G., and Guilfoyle, T. 2002. Auxin-responsive gene expression: Genes, promoters and regulatory factors. Plant Mol. Biol. 49:373-385.

Han, B., Zhu, Q., Ge, J., Xu, M. Y., and Dong, H. 2013. Molecular mechanisms underlying roles of the TTG2 protein in modulating NPR1-regulated pathogen defenses and ARF8-engaged development in tobacco. Plant Physiol. J. 49:1291-1230.

Hayashi, K. 2012. The interaction and integration of auxin signaling components. Plant Cell Physiol. 53:965-975.

Heidel, A. J., Clarke, J. D., Antonovics, J., and Dong, X. 2004. Fitness costs of mutations affecting the systemic acquired resistance pathway in Arabidopsis thaliana. Genetics 168:2197-2206.

Holm, R. E., and Key, J. L. 1969. Hormonal regulation of cell elongation in the hypocotyl of rootless soybean: An evaluation of the role of DNA synthesis. Plant Physiol. 44:1295-1302.

Huang, H., Wang, G., Zhao, Y., Shi, P., Luo, H., and Yao, B. 2010. Direct and efficient cloning of full-length genes from environmental DNA by RT-qPCR and modified TAIL-PCR. Appl. Microbiol. Biotechnol. 87:1141-1149.

Julliard, J., Sotta, B., Pelletier, G., and Miginiac, E. 1992. Enhancement of naphthaleneacetic acid-induced rhizogenesis in TL-DNA-transformed Brassica napus without significant modification of auxin levels and auxin sensitivity. Plant Physiol. 100:1277-1282.

Kaku, H., Nishizawa, Y., Ishii-Minami, N., Akimoto-Tomiyama, C. Dohmae, N., Takio, K., Minami, E., and Shibuya, N. 2006. Plant cells recognize chitin fragments for defense signaling through a plasma membrane receptor. Proc. Natl. Acad. Sci. U.S.A. 103:11086-11091

Kalluri, U. C., Difazio, S. P., Brunner, A. M., and Tuskan, G. A. 2007. Genome-wide analysis of Aux/IAA and ARF gene families in Populus trichocarpa. BMC Plant Biol. 7:59.

Kaltdorf, M., and Naseem, M. 2013. How many salicylic acid receptors does a plant cell need? Sci. Signal. 6:jc3.

Kumar, R., Agarwal, P., Tyagi, A. K., and Sharma, A. K. 2012. Genomewide investigation and expression analysis suggest diverse roles of auxin-responsive GH3 genes during development and response to different stimuli in tomato (Solanum lycopersicum). Mol. Genet. Genomics 287:221-235

Lawton, K., Weymann, K., Friedrich, L., Vernooij B., Uknes S., and Ryals, J. 1995. Systemic acquired resistance in Arabidopsis requires salicylic acid but not ethylene. Mol. Plant-Microbe Interact. 8:863-870.

Lee, J., Han, C. T., and Hur, Y. 2013. Molecular characterization of the Brassica rapa auxin-repressed, superfamily genes, BrARP1 and BrDRM1. Mol. Biol. Rep. 40:197-209.

Li, B. Y., Gao, R., Cui, R. Z., Lü, B. B., Li, X. J., Zhao, Y. Y., You, Z. Z, Tian, S. M., and Dong, H. 2012. Tobacco TTG2 suppresses resistance to pathogens by sequestering NPR1 from the nucleus. J. Cell Sci. 125:4913-4922.

Li, Y., Zhang, Q., Zhang, J., Wu, L., Qi, Y., and Zhou, J. M. 2010. Identification of MicroRNAs involved in pathogen-associated molecular pattern-triggered plant innate immunity. Plant Physiol. 152:2222-2231.

Liscum, E., and Reed, J. W. 2002. Genetics of Aux/IAA and ARF action in plant growth and development. Plant Mol. Biol. 49:387-400.

Liu, R., Chen, L., Jia, Z., Lü, B., Shi, H., Shao, W., and Dong. H. 2011. Transcription factor AtMYB44 regulates induced expression of the ETHYLENE INSENSITIVE2 gene in Arabidopsis responding to a harpin protein. Mol. Plant-Microbe Interact. 24:377-389.

Liu, S. Q., and Hu, L. F. 2013. Genome-wide analysis of the auxinresponse-factor gene family in cucumber. Genet. Mol. Res. 12:4317 4331

Livak, K. J., and Schmittgen, T. D. 2001. Analysis of relative gene expression data using real-time quantitative PCR and the $2^{-\Delta \triangle C T}$ method. Methods 25:402-408.

Lü, B., Sun, W., Li, L., and Dong, H. 2011. Nucleocytoplasmic trafficking for regulation of defense signaling in plants. J. Nanjing Agric. Univ. 34:129-137.

Lü, B., Li, X., Sun, W., Li, L., Gao, R., Zhu, Q., Tian, S., Fu, M., Yu, H., Tang, X., Zhang, C., and Dong, H. 2013. AtMYB44 regulates resistance to the green peach aphid and diamondback moth by activating EIN2affected defenses in Arabidopsis. Plant Biol. (Stuttg.) 15:841-850.

Ma, Y. H., Zhou, C. Y., and Sheng, C. S. 1979. Pages 186-189 in: Methods in Field Experiments and Statistical Analyses (in Chinese). Agriculture Press, Beijing.

Miya, A., Albert, P., Shinya, T., Desaki, Y., Ichimura, K., Shirasu, K., Narusaka, Y., Kawakami, N., Kaku, H., and Shibuya, N. 2007. CERK1, a LysM receptor kinase, is essential for chitin elicitor signaling in Arabidopsis. Proc. Natl. Acad. Sci. U.S.A. 104:19613-19618.

Mukhtar, M. S., Nishimura, M. T., and Dangl, J. 2009. NPR1 in plant defense: It's not over til it's turned over. Cell 137:805-806.

Müller, B., and Sheen, J. 2008. Cytokinin and auxin interaction in root 
stem-cell specification during early embryogenesis. Nature 453:10941098.

Navarro, L., Dunoyer, P., Jay, F., Arnold, B., Dharmasiri, N., Estelle, M., Voinnet, O., and Jones, J. D. 2006. A plant miRNA contributes to antibacterial resistance by repressing auxin signaling. Science 312:436-439.

Nitsch, J. P. 1952. Plant hormones in the development of fruits. Q. Rev. Biol. 27:33-57.

Palma, K. P., Zhang, Y. L., and Li, X. 2005. An importin $\alpha$ homolog, MOS6, plays an important role in plant innate immunity. Curr. Biol. 15:1129-1135.

Pang, Y., Wenger, J. P., Saathoff, K., Peel, G. J., Wen, J., Huhman, D., Allen, S. N., Tang, Y., Cheng, X., Tadege, M., Ratet, P., Mysore, K. S., Sumner, L. W., Marks, M. D., and Dixon, R. A. 2009. A WD40 repeat protein from Medicago truncatula is necessary for tissue-specific anthocyanin and proanthocyanidin biosynthesis but not for trichome development. Plant Physiol. 151:1114-1129.

Paranagama, M. P., Sakamoto, K., Amino, H., Awano, M., Miyoshi, H., and Kita, K. 2010. Contribution of the FAD and quinone binding sites to the production of reactive oxygen species from Ascaris sum mitochondrial complex II. Mitochondrion 10:158-165.

Peng, J. L., Bao, Z. L., Dong, H. S., Ren, H. Y., and Wang, J. 2004. Expression of harpin ${ }_{\mathrm{Xoo}}$ in transgenic tobacco induces pathogen defense in the absence of hypersensitive cell death. Phytopathology 94:1048-1055.

Piacenza, L., Irigoín, F., Alvarez, M. N., Peluffo, G., Taylor, M. C., Kelly, J. M., Wilkinson, S. R., and Radi, R. 2007. Mitochondrial superoxide radicals mediate programmed cell death in Trypanosoma cruzi: Cytoprotective action of mitochondrial iron superoxide dismutase overexpression. Biochem. J. 403:323-334.

Qian, Y. J., Mugiira, R. B., Zhou, X. P. 2006. A modified viral satellite DNA-based gene silencing vector is effective in association with heterologous begomoviruses. Virus Res. 118:136-142.

Quint, M., and Gray, W. G. 2006. Auxin signaling. Curr. Opin. Plant Biol. 9:448-453.

Ren, X., Zhang, C., Bao, Z., Chen, L., Wu, X., and Dong, H. 2008. Root growth of Arabidopsis thaliana is regulated by ethylene and abscisic acid signaling interaction in response to $\mathrm{HrpN}_{\mathrm{Ea}}$, a bacterial protein of harpin group. Plant Mol. Biol. Rep. 31:617-627.

Rensing, S. A., Lang, D., Zimmer, A. D., Terry, A., Salamov, A., Shapiro, H., Nishiyama, T., Perroud, P. F., Lindquist, E. A., Kamisugi, Y., Tanahashi, T., Sakakibara, K., Fujita, T., Oishi, K., Shin-I, T., Kuroki, Y., Toyoda, A., Suzuki, Y., Hashimoto, S., Yamaguchi, K., Sugano, S., Kohara, Y., Fujiyama, A., Anterola, A., Aoki, S., Ashton, N., Barbazuk, W. B., Barker, E., Bennetzen, J. L., Blankenship, R., Cho, S. H., Dutcher, S. K., Estelle, M., Fawcett, J. A., Gundlach, H., Hanada, K., Heyl, A., Hicks, K. A., Hughes, J., Lohr, M., Mayer, K., Melkozernov, A., Murata, T., Nelson, D. R., Pils, B., Prigge, M., Reiss, B., Renner, T., Rombauts, S., Rushton, P. J., Sanderfoot, A., Schween, G., Shiu, S. H., Stueber, K., Theodoulou, F. L., Tu, H., Van de Peer, Y., Verrier, P. J., Waters, E., Wood, A., Yang, L., Cove, D., Cuming, A. C., Hasebe, M., Lucas, S., Mishler, B. D., Reski, R., Grigoriev, I. V., Quatrano, R. S., and Boore, J. L. 2008. The Physcomitrella genome reveals evolutionary insights into the conquest of land by plants. Science 319:64-69.

Ryals, J. A., Neuenschwander, U. H., Willits, M. G., Molina, A., Steiner, H. Y., and Hunt, M. D. 1996. Systemic acquired resistance. Plant Cell 8:1809-1819.

Sang, S., Li, X., Gao, R., You, Z., Lü, B., Liu, P., Ma, Q., and Dong, H. 2012. Apoplastic and cytoplasmic location of harpin protein $\mathrm{Hpa} 1_{\mathrm{Xoo}}$ plays different roles in $\mathrm{H}_{2} \mathrm{O}_{2}$ generation and pathogen resistance in Arabidopsis. Plant Mol. Biol. 79:375-391.

Schiavone, F. M., and Cooke, T. J. 1987. Unusual patterns of somatic embryogenesis in the domesticated carrot: Developmental effects of exogenous auxins and auxin transport inhibitors. Cell Differ. 21:53-62.

Shin, R., Burch, A. Y., Huppert, K. A., Tiwari, S. B., Murphy, A. S., Guilfoyle, T. J., and Schachtman, D. P. 2007. The Arabidopsis transcription factor MYB77 modulates auxin signal transduction. Plant Cell 19:2440-2453.

Sloan, J., Backhaus, A., Malinowski, R., McQueen-Mason, S., and Fleming, A. J. 2009. Phased control of expansin activity during leaf development identifies a sensitivity window for expansin-mediated induction of leaf growth. Plant Physiol. 151:1844-1854.

Spoel, S. H., Mou, Z., Tada, Y., Spivey, N. W., Genschik, P., and Dong, X. 2009. Proteasome-mediated turnover of the transcription coactivator NPR1 plays dual roles in regulating plant immunity. Cell 137:860-872.

Strader, L. C., and Nemhauser, J. L. 2013. Auxin 2012: A rich mea ho'oulu. Development 140:1153-1157.
Sun, L. J., Ren, H. Y., Liu, R. X., Li, B. Y., Wu, T. Q., Sun, F., Liu, H. M. Wang, X. M., and Dong, H. S. 2010. An h-type thioredoxin functions in tobacco defense responses to two species of viruses and an abiotic oxidative stress. Mol. Plant-Microbe Interact. 23:1470-1485.

Tao, L. Z., Cheung, A. Y., Nibauand, C., and Wu, H. M. 2005. RAC GTPases in tobacco and Arabidopsis mediate auxin-induced formation of proteolytically active nuclear protein bodies that contain AUX/IAA proteins. Plant Cell 17:2369-2383.

Tao, X., and Zhou, X. 2004. A modified viral satellite DNA that suppresses gene expression in plants. Plant J. 38:850-860.

Tiwari, S. B., Wang, X. J., Hagen, G., and Guilfoyle, T. J. 2001. Aux/IAA proteins are active repressors, and their stability and activity are modulated by auxin. Plant Cell 13:2809-2822.

Tiwari, S. B., Hagen, G., and Guilfoyle, T. 2003. The roles of auxin response factor domains in auxin-responsive transcription. Plant Cell 15:533543.

Torres, M. A. 2010. ROS in biotic interactions. Physiol. Plant 138:414429.

Truman, W. M., Bennett, M. H., Turnbull, C. G., and Grant, M. R. 2010. Arabidopsis auxin mutants are compromised in systemic acquired resistance and exhibit aberrant accumulation of various indolic compounds. Plant Physiol. 152:1562-1573.

Ulmasov, T., Liu, Z. B., Hagen, G., and Guilfoyle, T. J. 1995. Composite structure of auxin response elements. Plant Cell 7:1611-1623.

Ulmasov, T., Murfett, J., Hagen, G., and Guilfoyle, T. J. 1997. Aux/IAA proteins repress expression of reporter genes containing natural and highly active synthetic auxin response elements. Plant Cell 9:19631971.

Ulmasov, T., Hagen, G., Guilfoyle, T. J. 1999. Activation and repression of transcription by auxin-response factors. Proc. Natl. Acad. Sci. U.S.A. 96:5844-5849.

Vanneste, S., and Friml, J. 2009. Auxin: A trigger for change in plant development. Cell 136:1005-1016.

Wan, J., Zhang, X. C., and Stacey, G. 2008. Chitin signaling and plant disease resistance. Plant Signal. Behav. 3:831-833.

Wang, D., Pajerowska-Mukhtar, K., Culler, A. H., and Dong, X. 2007. Salicylic acid inhibits pathogen growth in plants through repression of the auxin signaling pathway. Curr. Biol. 17:1784-1790.

Wang, Y., Liu, R., Chen, L., Wang, Y. C., Liang, Y. C., Wu, X., Li, B., Wu, J., Liang, Y., Wang, X., Zhang, C., Wang, Q., Hong, X., and Dong, H. 2009. Nicotiana tabacum TTG1 contributes to ParA1-induced signalling and cell death in leaf trichomes. J. Cell Sci. 122:2673-2685.

Wilmoth, J. C., Wang, S., Tiwari, S. B., Joshi, A. D., Hagen, G., Guilfoyle, T. J., Alonso, J. M., Ecker, J. R., and Reed, J. W. 2005. NPH4/ARF7 and ARF19 promote leaf expansion and auxin-induced lateral root formation. Plant J. 43:118-130.

Wu, T., Guo, A., Zhao, Y., Wang, X., Wang, Y., Zhao, D., Li, X., Ren, H, and Dong, H. 2010. Ectopic expression of the rice lumazine synthase gene contributes to defense responses in transgenic tobacco. Phytopathology 100:573-581.

Wu, X., Wu, T., Long, J., Yin, Q., Zhang, Y., Chen, L., Liu, R., Gao, T., and Dong, H. 2007. Productivity and biochemical properties of green tea in response to full-length and functional fragments of $\mathrm{HpaG}_{\mathrm{Xooc}}$, a harpin protein from the bacterial rice leaf streak pathogen Xanthomonas oryzae pv. oryzicola. J. Biosci. 32:1119-1131.

Yang, D. L., Yang, Y., and He, Z. 2013. Roles of plant hormones and their interplay in rice immunity. Mol. Plant 6:675-685.

Yu, I. C., Parker, J., Bent, A. F. 1998. Gene-for-gene disease resistance without the hypersensitive response in Arabidopsis dnd1 mutant. Proc. Natl. Acad. Sci. U.S.A. 95:7819-7824.

Zhu, Q., Li., B., Mu, S., Han, B., Cui, R., You, Z., and Dong, H. 2013. TTG2-regulated development is related to expression of putative AUXIN RESPONSE FACTOR genes in tobacco. BMC Genomics $14: 806$.

Zhu, Y., Du, B. J., Qian, J., Zou, B. H., and Hua, J. 2013. Disease resistance gene-induced growth inhibition is enhanced by rcd1 independent of defense activation in Arabidopsis. Plant Physiol. 161:2005-2013.

Zipfel, C., Robatzek, S., Navarro, L., Oakeley, E. J., Jones, J. D., Felix, G., and Boller, T. 2004. Bacterial disease resistance in Arabidopsis through flagellin perception. Nature 428:764-767.

\section{AUTHOR-RECOMMENDED INTERNET RESOURCE}

NCBI databases: www.ncbi.nlm.nih.gov 